OPEN ACCESS

Edited by:

Magdalena Arasimowicz-Jelonek, Adam Mickiewicz University, Poland

Reviewed by:

Ahmad Arzani,

Isfahan University of Technology, Iran

Dong-Ha Oh,

Louisiana State University,

United States

${ }^{*}$ Correspondence:

María Luisa Badenes

badenes_mlu@gva.es

Specialty section: This article was submitted to

Plant Abiotic Stress,

a section of the journal

Frontiers in Plant Science

Received: 23 March 2020

Accepted: 13 July 2020

Published: 07 August 2020

Citation:

Gil-Muñoz F, Pérez-Pérez JG,

Quiñones A, Naval MdM and

Badenes ML (2020) Intra and Interspecific Variability of Salt Tolerance Mechanisms in Diospyros Genus.

Front. Plant Sci. 11:1132.

doi: 10.3389/fp/s.2020.01132

\section{Intra and Inter-specific Variability of Salt Tolerance Mechanisms in Diospyros Genus}

\author{
Francisco Gil-Muñoz ${ }^{1}$, Juan Gabriel Pérez-Pérez ${ }^{2}$, Ana Quiñones ${ }^{1}$, María del Mar Naval ${ }^{1}$ \\ and María Luisa Badenes ${ }^{1 *}$ \\ ${ }^{1}$ Centro de Citricultura y Producción Vegetal, Instituto Valenciano de Investigaciones Agrarias (MIA), Valencia, Spain, ${ }^{2}$ Centro de \\ Investigación en Desarrollo de Agricultura Sostenible, Instituto Valenciano de Investigaciones Agrarias (MIA), Valencia, Spain
}

Saline stress is one of most important problems that agriculture must face in the context of climate change. In the Mediterranean basin, one of the regions most affected, persimmon production can be compromised by this effect, due to the limited availability of salt tolerant rootstocks. Seedlings coming from four populations from the Diospyros genus have been exposed to salt stress in order to identify salt tolerance genotypes within these populations. Morphological, physiological, and transcriptomic approaches have revealed different mechanisms of tolerance among the population studied. An HKT1like gene has been shown to have different root expression related to the salt tolerance phenotypes among and within populations. Additionally, we have observed differences in salt-responsive expression among PIP aquaporin genes. Genetic variability for salt tolerance can be generated in Diospyros species through crossings and used for overcome salt stress. Furthermore, differences in water use efficiency (WUE) have been obtained between and within populations. The information gathered at transcriptomic and physiological level demonstrated natural and heritable variability among Diospyros genus which is the key for salt-tolerant rootstock breeding programs.

Keywords: Diospyros, saline tolerance, rootstock breeding, persimmon, HKT-1 gene, salt stress

\section{INTRODUCTION}

Persimmon (Diospyros kaki) production in the Mediterranean has increased by five times in the last 20 years (Perucho, 2018). In fact, it became an important alternative to citrus production and shares the same crop areas. However, in the recent years, cultural practices and climate change have modified rainfall distribution and have increased salt content in the irrigation water (Visconti et al., 2015). In general, there are two major ways to tackle soil salinization problem, irrigation-anddrainage approach and improvement of salinity tolerance in crops. Saline soils are difficult to remediate, for several reasons that have been outlined by Arzani and Ashraf (2016), and thus the use of salinity tolerant varieties is the most effective and widely used approach. In tree crops composed by rootstock and scion, the best approach to overcome soil salinity is to use salt-tolerant rootstocks compatible with the scion (Forner-Giner and Ancillo, 2013). There are three species of Diospyros genus used as rootstocks: D. kaki, D. lotus, and D. virginiana (Badenes et al., 2015). D. lotus is the most commonly used rootstock in the Mediterranean area due to its tolerance to lime-filled soils, 
adaptability, and absence of basal shoots. However, it is high sensitive to salinity (de Paz et al., 2016a; Visconti et al., 2017). D. virginiana, is tolerant to salinity and has a good development in lime-filled soils, but it confers too much vigor to the scion and produces basal shoots, both of which are traits that make crop management difficult (Incesu et al., 2014; de Paz et al., 2016b). D. $k a k i$ is the most used rootstock species around the world, because its compatibility with all the cultivars. This rootstock is not used in the Mediterranean basin because its sensitivity to lime-filled soils and the weak root system developed in those soils that causes pour and slow development (Bellini and Giordani, 2002).

An additional problem for persimmon crop is the origin of the rootstocks; all of them come from seedlings, never from clonal propagation, which implies a high genetic variability among rootstocks. No clonal rootstocks nor clones selected from breeding programs are available, although micropropagation methods have been developed for some genotypes of D. lotus and D. virginiana (Giordani et al., 2012). Regarding to saline-stress performance, $D$. virginiana has been identified as the most salttolerant species and D. lotus the most sensitive, being $D$. kaki intermediate (de Paz et al., 2016b; Visconti et al., 2017; Gil-Muñoz et al., 2018a). However, information about the salt tolerance diversity into each rootstock species is not available. To unravel this question is the key for developing genotypes tolerant to salinity. Moreover, to determine the salt tolerance mechanisms among the persimmon rootstock species would allow to define strategies for managing the crop in saline environments and to design interspecific crosses that combined different tolerant mechanisms.

Salt stress tolerance is a polygenic (quantitative) trait highly influenced by environment and genotype-by-environment interaction (Arzani and Ashraf, 2016) (Tiwari et al., 2016). Therefore, discovering the salinity tolerance mechanism or even the genes underlying to the tolerant phenotypes might help to avoid the environment effect in the first steps of a breeding program. Salt stress causes osmotic stress and ion toxicity, leading to cell dehydration, disruption of metabolic processes, nutrient imbalances, membrane dysfunction, and oxidative stress (Essah et al., 2003) (Essah et al., 2003; Arzani, 2008; Munns and Tester, 2008).

Under salinity conditions, osmotic stress causes drought-like effects in the plant. It causes changes in the stomatal aperture of the plant via abscisic acid (ABA) route (Fricke et al., 2006). Independently to the water ion profile, this mechanism is activated and might be a drought response effect, as it has been observed that it is regulated by root signals that are also triggered in drought conditions (Termaat et al., 1985; Davies et al., 2005). Photosynthesis of the plant can be severely affected by salinity stress, but the causes are not yet fully known (Gil-Muñoz et al., 2020). Some studies have related salinity stress with an increase in stored carbohydrate (Munns et al., 2000), indicating a reduction in sink demand that may downregulate photosynthesis.

Regulation of water transport, small solutes, and hydric balance through the plant is a mechanism to overcome salinity stress. Maurel et al. (2008) described membrane intrinsic proteins named aquaporins that play a central role in water relations of roots, leaves, and seeds, hence, involved in this regulation. Several studies described changes in aquaporin Plasma membrane intrinsic protein (PIPs) family activity under salt stress (Martínez-Ballesta et al., 2003; Boursiac et al., 2005; López-Pérez et al., 2009) linked to a reduction in hydraulic conductivity (Joly, 1989; Zekri and Parsons, 1989). Furthermore, in citrus rootstocks, it has been observed different aquaporin activity in salt-tolerant genotypes compared to sensitive (Rodríguez-Gamir et al., 2012). Furthermore, experiments on yeast and Xenopus oocytes have shown increased $\mathrm{Na}^{+}$conductance when overexpressing AtPIP2;1 from Arabidopsis thaliana, suggesting a possible function for $\mathrm{Na}^{+}$influx into the plant (Chaumont and Tyerman, 2014).

Several genes have been identified with salt tolerance, mainly with ionic stress overcame by avoiding toxic ion inflow, transport, or by balancing ion homeostasis (Arzani and Ashraf, 2016). The Salt Overly Sensitive (SOS) signaling pathway is responsible of maintaining ion homeostasis during salt stress (Zhu et al., 1998). In this pathway, myristoylated calcium-binding protein CBL4 (SOS3) acts as a sensor to perceive the $\mathrm{Na}^{+}$-mediated $\mathrm{Ca}^{2+}$ spike. After activation, it interacts with a serine/threonine protein kinase (SOS2) (Liu and Zhu, 1998; Halfter, 2000; Liu, 2000; Hrabak et al., 2003) that mediates the activation of the target gene SOS1 (Shi et al., 2000; Qiu et al., 2002; Quintero et al., 2002; Quan et al., 2007; Quintero et al., 2011), a plasma membrane encoding gene with $\mathrm{Na}^{+} /$ $\mathrm{H}^{+}$antiporter activity (Qiu et al., 2003) that mediates the retrieval of $\mathrm{Na}^{+}$from the cytosol. However, this pathway has a high demand of energy and can compromise plant growth (Isayenkov and Maathuis, 2019). Other genes related with salt stress tolerance participate in different tolerance mechanisms. Some members of the HKT (High affinity potassium transporter) family have been linked with $\mathrm{Na}^{+}$exclusion (Byrt et al., 2007; Munns and Tester, 2008; Almeida et al., 2013; Isayenkov and Maathuis, 2019) showing a higher expression in roots than shoots (Arabbeigi et al., 2018). Also, a member from the $\mathrm{Na}^{+} / \mathrm{H}^{+}$exchanger family (NHX) has been liked to salinity tolerance (Apse et al., 1999), possibly via a role in stomatal regulation (Barragán et al., 2012). Furthermore, the ALMT (Aluminum-activated Malate Transporter) protein family encodes anion transmembrane channels (Barbier-Brygoo et al., 2011) that have been proposed to have a role in $\mathrm{Cl}^{-}$and $\mathrm{Na}^{+}$sequestration in vacuoles of salt tolerant plants (Baetz et al., 2016).

Plants have developed extensive $\mathrm{Na}^{+}$tolerance mechanisms. Therefore, in saline environments $\mathrm{Cl}^{-}$can become potentially more harmful than $\mathrm{Na}^{+}$, as $\mathrm{Cl}^{-}$influx is believed to be mediated by passive mechanisms through anion channels regulated by ABA (Munns and Tester, 2008).

In a previous study, variability of salt tolerance in two Diospyros genus species was exploited and studied through interspecific crossings (Gil-Muñoz et al., 2020). However, despite prior works that studied salt stress effect in several Diospyros species (Mickelbart and Marler, 1998; Incesu et al., 2014), the mechanisms that regulate the osmotic and ionic stress tolerance within the species used as rootstock in persimmon remain not fully known. Understanding and identifying the mechanisms of salt tolerance present in the natural variability of these species will help to advance in rootstock breeding programs. Screening of physiological parameters and genetic expression of genes involved in tolerance is the strategy proposed 
for selecting genetic-dependent salt tolerant individuals. Results will provide insights of the mechanisms of tolerance in the persimmon species used as rootstocks. The discovery of the mechanisms for salt tolerance will provide tools for breeding Diospyros rootstocks better adapted to the saline conditions present in the Mediterranean basin environment.

\section{MATERIALS AND METHODS}

\section{Plant Material and Salinity Treatment}

Four populations were used for the salinity tolerance study: Seedlings from an open pollination family of D. kaki (DK), seedlings from open pollination family of $D$. virginiana (DV), seedlings from a half-sibling backcross family between D. kaki $x$ D. virginiana $(\mathrm{BC})$ and a population from $D$. lotus (DL), a full sibling family from a cross between two D. lotus trees at the IVIA persimmon germplasm bank was added to the study (Supplementary Figure 1). At the end of March, seeds were stratified for 30 days in plastic bags filled with perlite in a cold chamber at $4^{\circ} \mathrm{C}$. After stratification, seeds were transferred to peat-moss and perlite (4:1 ratio, respectively) and kept in a greenhouse at $18-24^{\circ} \mathrm{C}$ during 2 months (from April 24 to June 26, 2017).

One hundred and twenty-seven seedlings of each population were transplanted into $1-\mathrm{L}$ pots containing coarse sand to ensure complete drain. The plants were distributed randomly in the greenhouse and watered with a nutrient solution (3\% Cristaljisa 18-18-18, soluble fertilizer with micronutrients) until apical meristem growth was observed. The plants were acclimated before exposition to salinity treatment, meaning that they were watered with the nutrient solution until normal growth was observed. After acclimation, plants were submitted to a salinity treatment during 60 days. The treatment consisted in $40 \mathrm{mM} \mathrm{NaCl}$ added to the nutrient solution. All the watering of the plants was done three times a day with exclusively nutrient solution with $40 \mathrm{mM} \mathrm{NaCl}$ until water leakage to ensure soil washing between waterings. Although this salt concentration may appear to be mild, it was chosen based on our previous findings in persimmon (Gil-Muñoz et al., 2018a). The control plants remained watered with the standard nutrient solution.

\section{Agro-Morphological Data}

The parameters total height $(\mathrm{cm})$, leaves (no.), nodes (no.), internodes $(\mathrm{cm})$, and defoliation (1-no. leaves/no. nodes) were measured at days 0,30 , and 45 for all plants (127 of each population). Twenty plants (10 tolerant and 10 sensitive) of each family were selected based on salt tolerance according to the visual and agro-morphological data for further analyses. For the D. lotus family only five plants could be selected as tolerant. Ten control plants of each population were randomly selected. At the end of the salinity treatment (day 60), prior parameters were also measured for selected plants. Variables related to growth were calculated as the ratio between initial and final value. Relative growth rate (RGR) was calculated as follows:

$$
\mathrm{RGR}=\frac{\text { Ln(Height } 2-\text { Height } \quad 1)}{t 2-t 1}
$$

Based on visual symptoms, salinity injury was rated from 0 to 4: 0 , no symptoms; 1 , leaf turgor loss; 2 , leaf tip necrosis; 3 , leaf margin necrosis; 4, defoliated plant (Supplementary Figure 2).

\section{Stem Water Potential}

Stem water potential $\left(\psi_{\mathrm{H}}, \mathrm{MPa}\right)$ was measured in three fully expanded leaves of each plant from control and selected plants in a sunny day using a Model 600 Schölander Pressure Chamber (PMS Instrument Company, Albany, OR, USA) at the end of the salinity treatment (day 60). Previously, the leaves was kept in a reflective plastic bag for $30 \mathrm{~min}$ to remove water loss (Levin, 2019).

\section{Leaf Gas Exchange Parameters}

Leaf net $\mathrm{CO}_{2}$ assimilation rate $\left(\mathrm{A}_{\mathrm{CO} 2}\right)$, stomatal conductance $\left(\mathrm{g}_{\mathrm{s}}\right)$, leaf transpiration rate $(\mathrm{E})$, and internal $\mathrm{CO}_{2}$ concentration $\left(C_{i}\right)$ were measured on single attached leaves from selected (tolerant, sensitive, and control) plants. Determinations were performed using three uniform fully expanded leaves from the mid-stem zone. Intrinsic leaf water use efficiency (WUE) was calculated as $\mathrm{A}_{\mathrm{CO} 2}$ and $\mathrm{g}_{\mathrm{s}}$ ratio. All measurements were carried out in a sunny day between 9:30 a.m. and 12:30 p.m. at the end of the salt treatment (day 60). Photosynthetically active radiation (PAR) at the leaf surface was adjusted to a photon flux density of $1.000 \mu \mathrm{mol} \mathrm{m} \mathrm{m}^{-2} \mathrm{~s}^{-1}$. A CIRAS-2 Portable Photosynthesis System (PP Systems, Amesbury, Massachusetts, USA) was used for the measurements. Leaf laminae were fully enclosed within a PLC 6 (U) universal leaf autocuvette in a closed-circuit model and kept at $25 \pm 0.5^{\circ} \mathrm{C}$, with a leaf-to-air vapor deficit of about $1.7 \mathrm{kPa}$. The air flow rate through the cuvette was $0.5-1.5 \mathrm{~L} \mathrm{~min}^{-1}$.

\section{Ion Content Analysis}

After saline treatment, three leaves from each selected plant (control, tolerant, and sensitive plants) were collected. Sample pre-treatments for ion content measurement were performed as described in Gil-Muñoz et al. (2018b). Chloride concentration $\left(\mathrm{mg} \mathrm{ml}^{-1}\right)$ was determined by silver ion-titration (Gilliam, 1971) with a Corning 926 automatic chloridometer (Corning Ltd. Halstead Essex, UK). $\mathrm{Na}^{+}, \mathrm{Ca}^{2+}, \mathrm{K}^{+}, \mathrm{Mg}^{2+}, \mathrm{P}$, and $\mathrm{S}$ ions were quantified ( $\mathrm{mg} \mathrm{g}^{-1}$ dry w.t.) using a multiple-collector inductively coupled plasma mass spectrometry (MC-ICP MS, Thermo Finnigan Neptune).

\section{Gene Expression Analysis}

Young fully expanded leaves and root tip tissue was collected after 60 days of salt treatment and immediately frozen and powdered using liquid nitrogen. Control samples from all populations were also collected and processed. Three biological replicates were collected for each individual. RNA was isolated according to Gambino et al. (2008). DNA was removed with the RNase-Free DNase Set (Qiagen, Valencia, CA, USA), using the RNeasy Plant Mini Kit (Qiagen). Purified RNA (500 ng) was reverse transcribed with PrimeScript RT Reagent Kit (Takara Bio, Otsu, Japan) in a total volume of $10 \mu \mathrm{l}$. 
Six putative orthologous genes involved in different mechanisms leading to salt tolerance were analyzed SOS1, SOS2, SOS3, NHX1, HKT1, and ALMT9 with primers designed from D. lotus SRA archive (SRA ID: SRP045872) cv. Kunsenshi (Akagi et al., 2014). For the PIP aquaporin expression analysis, Arabidopsis thaliana PIP genes from the PIP1 and PIP2 families were blasted against the $D$. lotus (SRA ID: SRP045872) cv. Kunsenshi (Akagi et al., 2014). The output fragments were manually assembled to complete putative orthologous genes. Specific persimmon primers were designed using the sequences obtained (Table 1). For PIP expression analysis, individual biological replicates were mixed into three global biological replicates for each population subset.

The first-strand cDNA was 30 -fold diluted, using $1 \mu \mathrm{l}$ as template in a final volume of $20 \mu \mathrm{l}$. Quantitative real-time PCR was performed on a StepOnePlus Real-Time PCR System (Life Technologies, Carlsbad, CA, USA), using SYBR premix Ex Taq (Tli RNaseH plus) (Takara Bio). The PCR protocol consisted of $10 \mathrm{~min}$ at $95^{\circ} \mathrm{C}$, followed by 40 cycles of $15 \mathrm{~s}$ at $95^{\circ} \mathrm{C}$, and $1 \mathrm{~min}$ at $60^{\circ} \mathrm{C}$. The specificity of the reaction was assessed by the presence of a single peak in the dissociation curve and through size estimation of the amplified product by agarose electrophoresis. DkACT (Akagi et al., 2009) and DkTUA (Wang et al., 2016) were used as reference genes. The normalization factor was calculated by the geometric mean of the values of relative expression of both genes.

TABLE 1 | Primers used for RT-qPCR analysis.

\begin{tabular}{|c|c|}
\hline Gene name & Sequence (5'-3') \\
\hline \multirow[t]{2}{*}{ SOS1-Like } & F: GGATाICTCTGGAAGGAAAGTGCTA \\
\hline & R: GGAGATGTAATCAGTTCCTCTITGACAC \\
\hline \multirow[t]{2}{*}{ SOS2-Like } & F: TTAGAGTTGTTACTGGAGGGGAACT \\
\hline & R: CACTCAGTCCAAAGTCAGAAACCTTCA \\
\hline \multirow[t]{2}{*}{ SOS3-Like } & F: GAAGTTGAGGCCTTGTATGAGCTATाT \\
\hline & R: CCTAATGAACGAACAAATTCTCCAAACTC \\
\hline \multirow[t]{2}{*}{ HKT1-Like } & F: GATTCCTAACCCTGCAGATAAACCCATT \\
\hline & R: GTTGCAGACACAGAGGTAAAGAACAAG \\
\hline \multirow[t]{2}{*}{ NHX1-Like } & F: CACCAAAGAACTTGACAAGAATGCTG \\
\hline & R: CCAATAGTAGTGCACGGTACGAG \\
\hline \multirow[t]{2}{*}{ ALMT9-Like } & F: ACTTATGCAAAACTATACCCCACAATG \\
\hline & R: TAGATAAACATATTCACCACCAAACACAC \\
\hline \multirow[t]{2}{*}{ PIP1-1-Like } & F: CCCCAACAAGTGCTCCAGC \\
\hline & R: CTTGGTGTAGCCGGAGCTG \\
\hline \multirow[t]{2}{*}{ PIP1-2-Like } & F: TCACCTAGCAAGTGTGCCTCC \\
\hline & R: CCTTGGTGTAGCCATGCTGC \\
\hline \multirow[t]{2}{*}{ PIP1-3-Like } & F: GGCTCCCAACAAGTGTGCTT \\
\hline & R: CCTTGGTGTAGCCATGTGCA \\
\hline \multirow[t]{2}{*}{ PIP1-4-Like } & F: TCAGGTCTCCTACCAAGTGTGG \\
\hline & R: CCCTTGGTATAGCCAGGGTIT \\
\hline \multirow[t]{2}{*}{ PIP2-1-Like } & F: AAGTGAGCGAAGAGGGCCAAAC \\
\hline & R: GTAGCGACGGTGACGTAGAGG \\
\hline \multirow[t]{2}{*}{ PIP2-2-Like } & F: ATCTGAGCGAGGAAGGCCAAG \\
\hline & R: GTGGCGACGGTGACGTAGAGA \\
\hline \multirow[t]{2}{*}{ PIP2-3-Like } & F: CCACATTAACCCAGCAGTGACA \\
\hline & R: CCGATGATCTCAGCTCCGAGT \\
\hline \multirow[t]{2}{*}{ PIP2-4-Like } & F: AGGAAAGTGTCGCTGATCCGG \\
\hline & R: TTGCTGTAGCCGTGAGCCACCGAA \\
\hline \multirow[t]{2}{*}{ PIP2-5-Like } & F: GAGGAAGGTGTCGCTGATCAGA \\
\hline & R: TGTTGTAGCCTGACGCCACCTCA \\
\hline \multirow[t]{2}{*}{ PIP2-6-Like } & F: ATTGCTCTTCCTCTACGTCTCAGTG \\
\hline & R: GCGACACCTTCCTGGCTAACAG \\
\hline
\end{tabular}

\section{Statistical Analyses and Raw Data}

All the data analysis and graphics were made using RStudio v1.1.447 (2018) with packages from the Comprehensive R Archive Network (CRAN). Parameters for all the populations were statistically tested by Kruskal-Wallis test $(P \leq 0.05)$ and averages were compared with the Pairwise Wilcoxon-MannWhitney test at $95 \%$ confidence level $(\mathrm{P} \leq 0.05)$ using the packages dplyr (Wickham et al., 2018), ggplot2 (Wickham, 2016), FSA (Ogle et al., 2018), DescTools (Signorell, 2017), rcompanion (Mangiafico, 2018), RColorBrewer (Neuwirth, 2014), and multcompView (Graves et al., 2015). Principal component analysis (PCA) and correlogram were carried out using the packages ggplot2 (Wickham, 2016), factoextra (Kassambara and Mundt, 2017), and corrplot (Wei and Simko, 2016). The variables included were the agro-morphological traits measured before the selection. A biplot of individual scores and loadings was obtained. For representation of the RNA expression data, packages gplots (Warnes et al., 2016) and RColorBrewer (Neuwirth, 2014) were used.

All the raw data has been deposited in https:/github.com/ fragimuo/Diospyros-salt-tolerance.

\section{RESULTS}

\section{Saline Stress Effect Among Populations}

Initial morphological parameters from the four populations were measured before salinity treatment began (Figure 1). The number of days from sowing to germination showed differences between all the populations. D. kaki (DK) population resulted in the smallest plants and D. lotus (DL) plants the tallest, backcross (BC), and D. virginiana (DV) populations had a similar initial height. No differences were observed in initial node number between DK and BC population and between DL and DV. Interestingly, the highest variability in initial phenotype was found in $\mathrm{DV}$ and $\mathrm{BC}$ populations compared to $\mathrm{DK}$ and DL populations.

After 45 days of saline stress, differences were noticeable among the four populations (Figure 2). DV and BC reached higher height than DL and DK populations. The BC population reached the highest internode length compared to other populations, suggesting higher vigor under salinity conditions. Again, more variability was observed among DV and $\mathrm{BC}$ populations compared to $\mathrm{DK}$ and $\mathrm{DL}$ regarding to morphological parameters. Furthermore, some of the plants did not survive to the salt stress treatment. The survival rate after 45 days of saline treatment was $100 \%$ for BC, $87 \%$ for DV, $89 \%$ for DK, and $98 \%$ for DL. Comparing the morphological traits before and after the saline treatment, DV and BC populations had less detrimental effects than DK and DL populations that showed significantly reduced height and severe salt stress damage (Figure 3).

All the morphological variables measured during the stress treatment were submitted to a Principal Component Analysis (PCA) (Figure 4). The first two components explained almost $60 \%$ of total variability. The PCA grouped clearly the individuals 

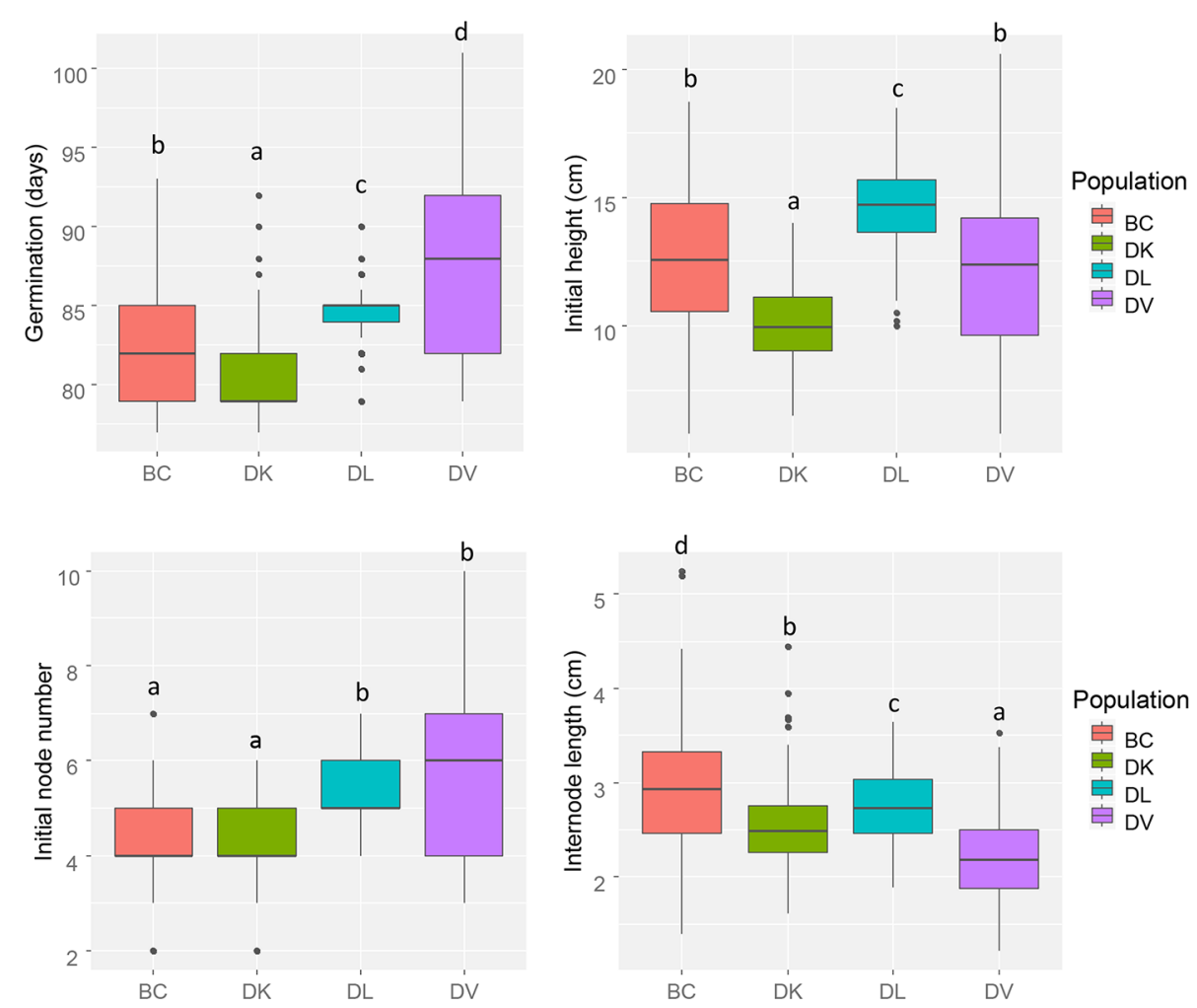

FIGURE 1 | Box and whisker representation of initial morphologic parameters of the four populations $(n=128)$. Different letters mean statistical differences between populations.

according to the population they belonged, but separated the populations DV, DK, and DL. The backcross population that combines genetic background from $D$. kaki and D. virginiana is located at equidistance from DK and DV populations. Furthermore, the DL dispersion was the narrowest. DV, BC, and DK population are separated by the PC1. The variables contributing to the PC1 were final plant height, final number of nodes, and relative final height (Supplementary Figure 3). DL population was separated from the other three by variables contributing to the $\mathrm{PC} 2$, final internode length, height growth, and defoliation.

\section{Saline Stress Tolerance Variability Within Populations}

Using the symptoms and overall plant status, subsets of tolerant and sensitive plants were chosen from each population. The observed symptoms and the scale used are shown on Supplementary Figure 2. The tolerant plants were a subset of plants showing less damage caused by salt, and the sensitive ones were the most affected within the population's species. These subsets were submitted to a PCA using the morphological variables, but removing those that showed a high collinearity in the previous PCA (Figure 5A). In the four populations sensitive and tolerant plants were grouped apart. DK, BC, and DL were separated on similar directions, according to the PCA variables final height and height growth (Figure 5B). DV population showed less clear separation between tolerant and sensitive plants, mainly in the PC2 axis. All the populations showed a coherency in the separation between tolerant and sensitive plants (Figure 5C), which implies that the morphological traits used are a useful tool for phenotyping salt tolerance. Due to the higher tolerance to salinity in the DV population, the discrimination by phenotype was weaker.

A correlogram using the morphological variables was done, including the leaf damage symptoms (Supplementary Figure 4). The height growth parameter and the relative final height were the variables more correlated with final salt damage symptoms. Differences for both variables were found between tolerant and sensitive individuals in the DK, DL, and $\mathrm{BC}$ populations (Figure 6). Furthermore, in these populations, the control plants had higher values than both the tolerant and sensitive subsets, except for the DK population in which the control plants were statistical identical to the tolerant subset regarding to height. No significant differences were found within the DV population.

\section{Physiological and Nutritional Effects Related to Salinity Tolerance}

In order to elucidate the salinity tolerance mechanisms within each species and population, once the populations were divided 
A
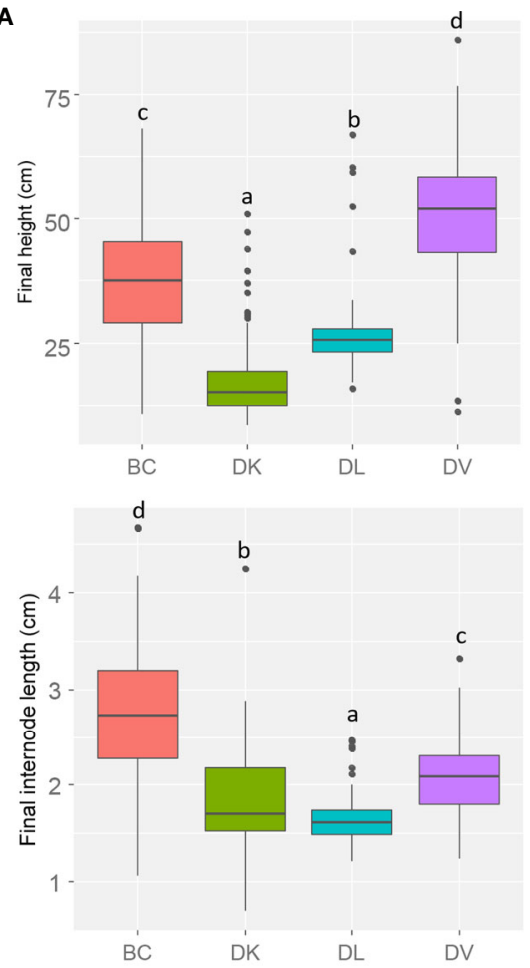

B

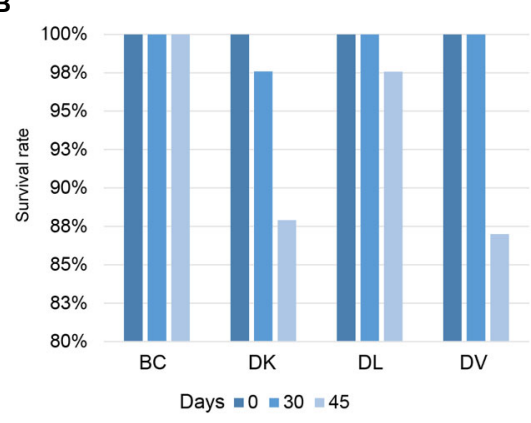

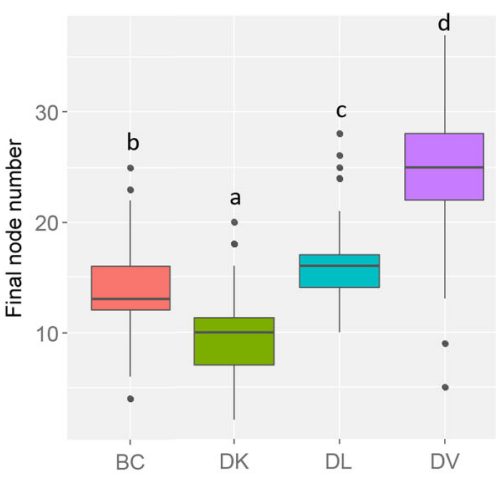

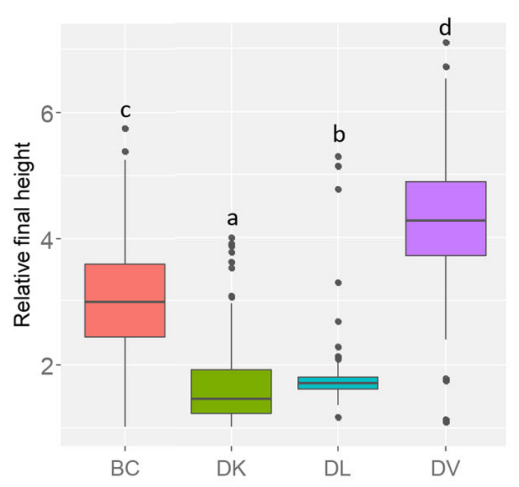

C

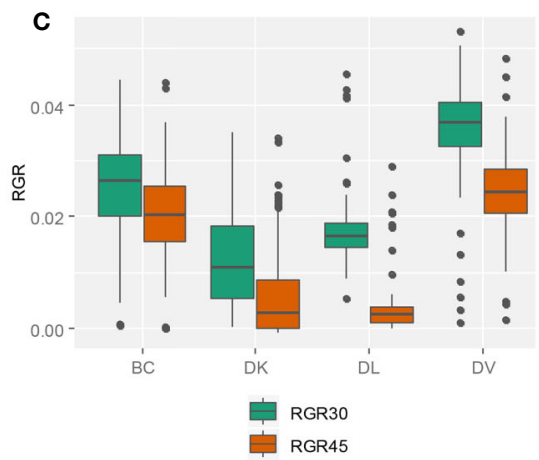

FIGURE 2 | Box and whisker representation of morphologic parameters of the four populations ( $\mathrm{n}=128)$ after 45 days of salt treatment (A). Different letters mean statistical differences between populations. Relative final height is the ratio between final and initial height. Percentage of plants that were still alive after 30 and 45 days of treatment (B). Relative growth rate of $0-30$ days and 30-45 days (C).

into subsets of tolerant and sensitive plants to saline stress, we analyzed plant water status, leaf gas exchange, and nutritional parameters for each subset after 60 days of saline stress.

Stem water potential was measured to determine differences in plant water status between the different populations. Sensitive plants showed significant better plant water status (higher values of stem water potential) than the tolerant in both DK and DL populations (Figure 7). In addition, in these populations, the values of stem water potential from the tolerant subset and the control were statistically identical. Respect to the leaf gas exchange parameters, all tolerant populations maintained similar values of $\mathrm{A}_{\mathrm{CO} 2}$ and $\mathrm{g}_{\mathrm{s}}$ than control plants, whereas in sensitive subsets from DK and DL were significantly decreased (Figures $8 \mathbf{A}, \mathbf{B}$ ). The $C_{i}$ were significantly higher in both sensitive and tolerant DK and DL populations than in control plants (Figure 8C). In the case of $\mathrm{BC}$ populations, $\mathrm{C}_{\mathrm{i}}$ were significantly lower in tolerant than in sensitive plants, whereas $C_{i}$ remained unaltered in DV plants. On the other hand, the DK and DL populations showed significantly lower WUE in both tolerant and sensitive plants than in the control (Figure 8D). The BC population had higher WUE in tolerant plants than in sensitive. No differences were observed between any population subset of DV.

Leaf ions content were analyzed to quantify toxic ion accumulation $\left(\mathrm{Cl}^{-}\right.$and $\left.\mathrm{Na}^{+}\right)$and nutritional imbalances $\left(\mathrm{K}^{+}\right.$ and $\mathrm{Ca}^{2+}$ ) caused by saline stress. Leaf $\mathrm{Cl}^{-}$accumulation significantly increased in both sensitive and tolerant populations (Figure 9A), but in DL populations sensitive plants had higher 


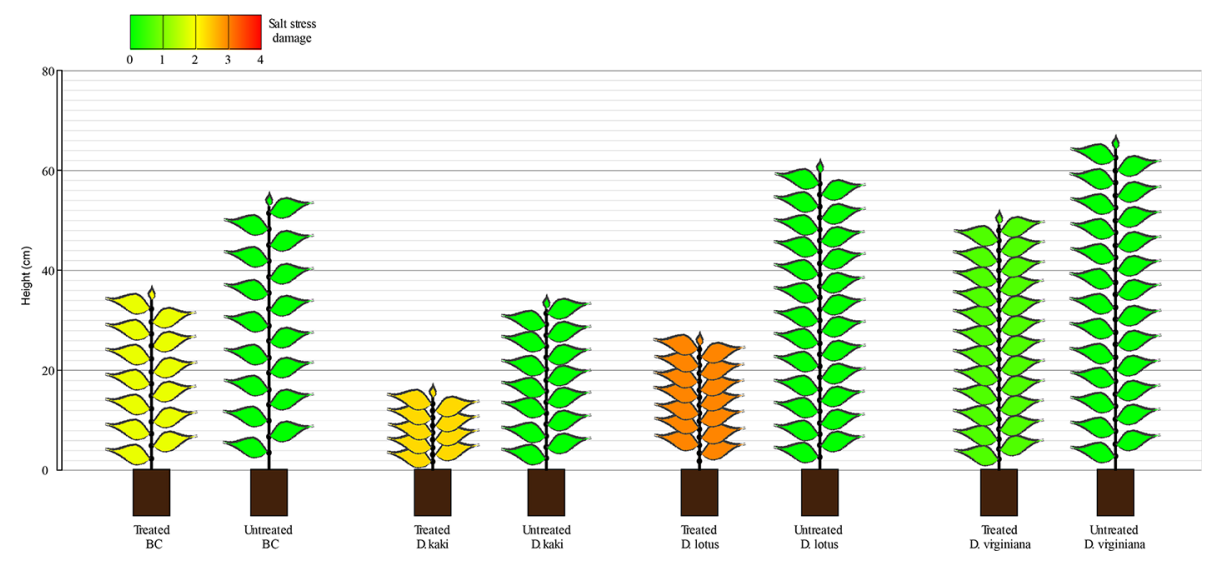

FIGURE 3 | Representation of mean plants from each population with $(n=128)$ and without salt (control; $n=15$ for DK, DV, and BC; $n=4$ for DL) after 45 days of treatment (prior to plant selection). Height (cm) number of nodes, defoliation (as missing leaves), and salt stress damage are depicted.
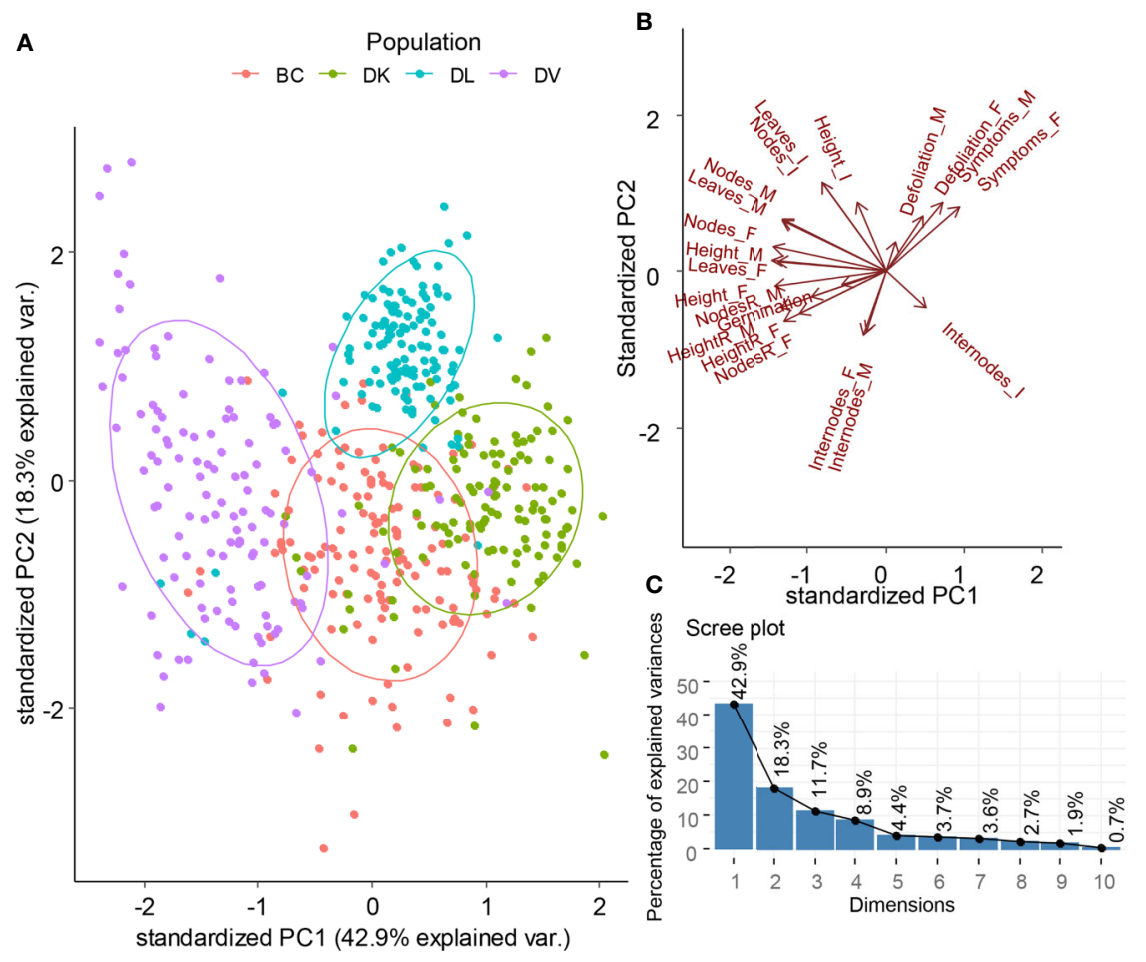

FIGURE 4 | Plot of the first two components from Principal Component Analysis of the morphological variables (A). Projection of the variables on the first two components (B). Scree plot of the dimensions and explained variability for each component (C).

leaf $\mathrm{Cl}^{-}$content than tolerant plants (Table 2). Regarding to leaf $\mathrm{Na}^{+}$accumulation, on DV and BC populations, $\mathrm{Na}^{+}$foliar content was higher on sensitive than tolerant subsets (Table 2; Figure 9B), whereas on DK and DL populations no differences were observed between tolerant and sensitive subsets. Comparing leaf $\mathrm{Na}^{+}$ accumulation between populations, DV showed the lowest values. Control plants had lower $\mathrm{Na}^{+}$content in all populations (Figure 9B).
Analyzing the nutritional imbalances caused by salinity, the $\mathrm{K}^{+}$content in the $\mathrm{BC}$ population was higher in tolerant plants than sensitive ones, being both significantly higher than the control plants. However, in the DK a lower $\mathrm{K}^{+}$is observed in the control plants compared to the sensitive and tolerant subsets. No significant differences are observed in DL and DV populations (Table 2). Regarding to $\mathrm{Ca}^{2+}$ content, it was lower in tolerant plants than in control, but without differences with the sensitive 

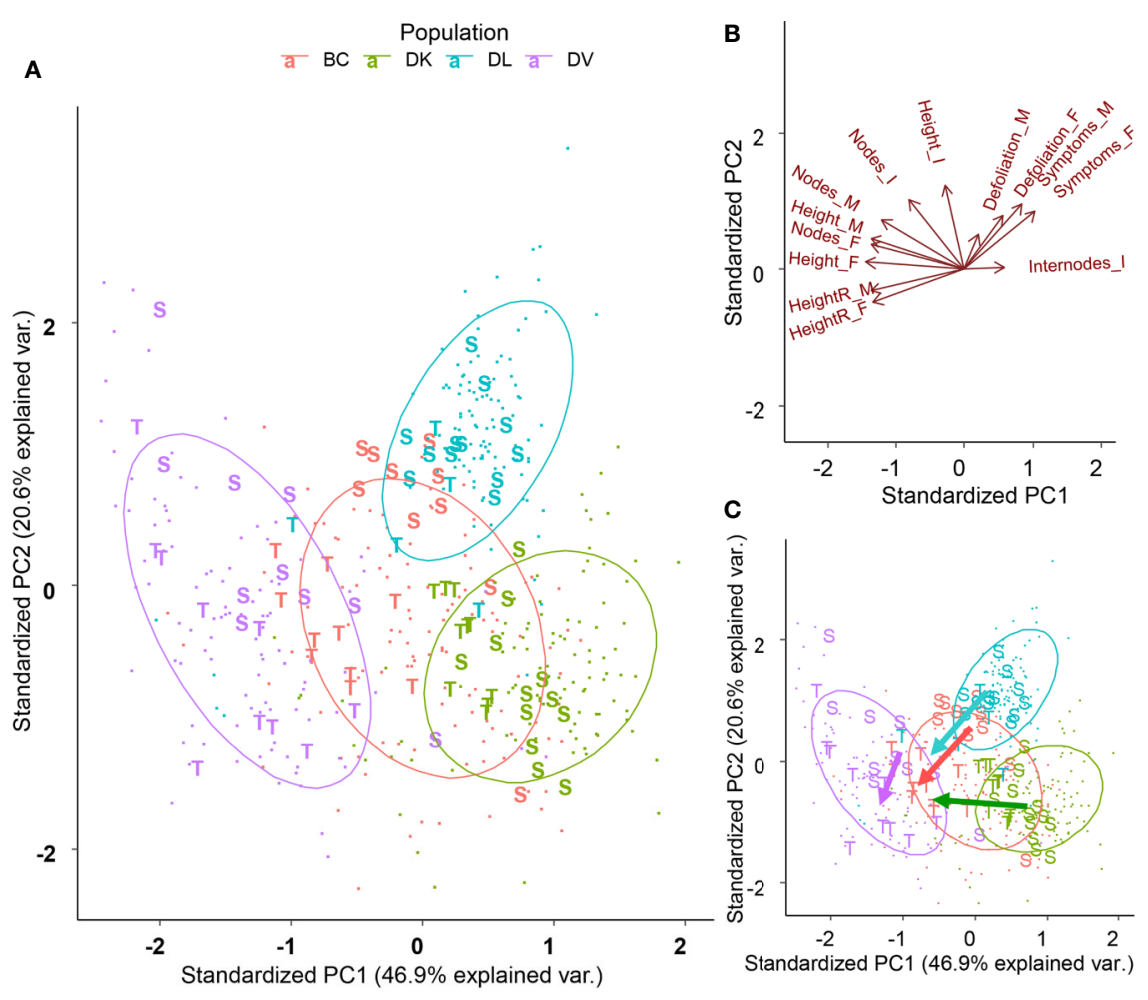

FIGURE 5 | Plot of the first two components from Principal Component (PC) Analysis of the morphological variables after removal of highly collinear variables (A). Plants selected as Tolerant and Sensitive according its phenotype have been represented. Projection of the variables on the first two components (B). Dimensional division between tolerant and sensitive subsets for each population (C).

subset. Nutrient balances were also calculated for $\mathrm{Na}^{+} / \mathrm{K}^{+}, \mathrm{Na}^{+} /$ $\mathrm{Ca}^{2+}$. The $\mathrm{Na}^{+} / \mathrm{K}^{+}$balance increased in all salinized plants, but differences between tolerant and sensitive plants were only observed in the BC population (Figure 9B). In all populations the control plants had the lowest $\mathrm{Na}^{+} / \mathrm{K}^{+}$ratio. Similar results were obtained for $\mathrm{Na}^{+} / \mathrm{Ca}^{2+}$, except that in $\mathrm{DV}$ population differences were observed among all subsets.

\section{Differential Expression of Genes Related to Salinity Tolerance}

Differential expression of genes related to salt-tolerance was analyzed in leaves and roots of five individuals of each subset at the end of the salt treatment (60 days). Control plants were included in the analysis (Supplementary Figure 5). Leaf expression of SOS1-like, SOS2-like and ALMT9-like was similar among all the populations and different in root tissue. HKT1-like expression on leaf was undetectable in all populations, but detectable in roots, being the lowest expression in DL. On the other hand, NHX1.1-like highest expression in leaf corresponded to $\mathrm{DV}$ population and in roots to BC. In order to compare between tolerant and sensitive subsets, all gene expression was relative to the control plants of each population and a heatmap was constructed using the Log2fold change (Figure 10). On leaves, SOS3-like expression was downregulated on both subsets of DK population under salt treatment, whereas an upregulation was observed in the DL population. Interestingly, an upregulation was observed only in the sensitive subset of the BC population on $4 / 5$ plants. Regarding to roots, SOS2-like expression was downregulated under salt treatment on the $\mathrm{BC}$ population, whereas SOS3-like was upregulated. ALMT9-like gene expression was upregulated on sensitive BC subset. About HKT1-like gene expression, a downregulation has observed in sensitive subset of BC and DL populations, whereas in tolerant DL subset and DV population a higher expression has been observed.

After obtaining the sequences of the putative orthologues of PIPs in Diospyros lotus, a phylogenetic tree was constructed (Supplementary Figure 6). PIP1-like family of D. lotus was grouped together with the PIP1 Arabidopsis thaliana genes, whereas D. lotus PIP2-like genes were grouped with the $A$. thaliana PIP2 genes. Expression of PIP1-like and PIP2-like aquaporin families were analyzed and compared between tolerant and sensitive subset bulks for each population. A heat map was constructed using the control bulk for normalizing within populations (Figure 11). On the BC population, PIP2-like 5 showed a four-fold upregulation on leaves from sensitive plants compared to tolerant, Furthermore, PIP2-like 6 and PIP1-like 1 showed a downregulation in sensitive plants compared to tolerant in leaves and roots, respectively. For these genes, the tolerant plants had similar levels of expression to the control plants. Regarding to the DK population; comparing sensitive to tolerant leaves, PIP1-like 1 and PIP2-like 5 showed a 


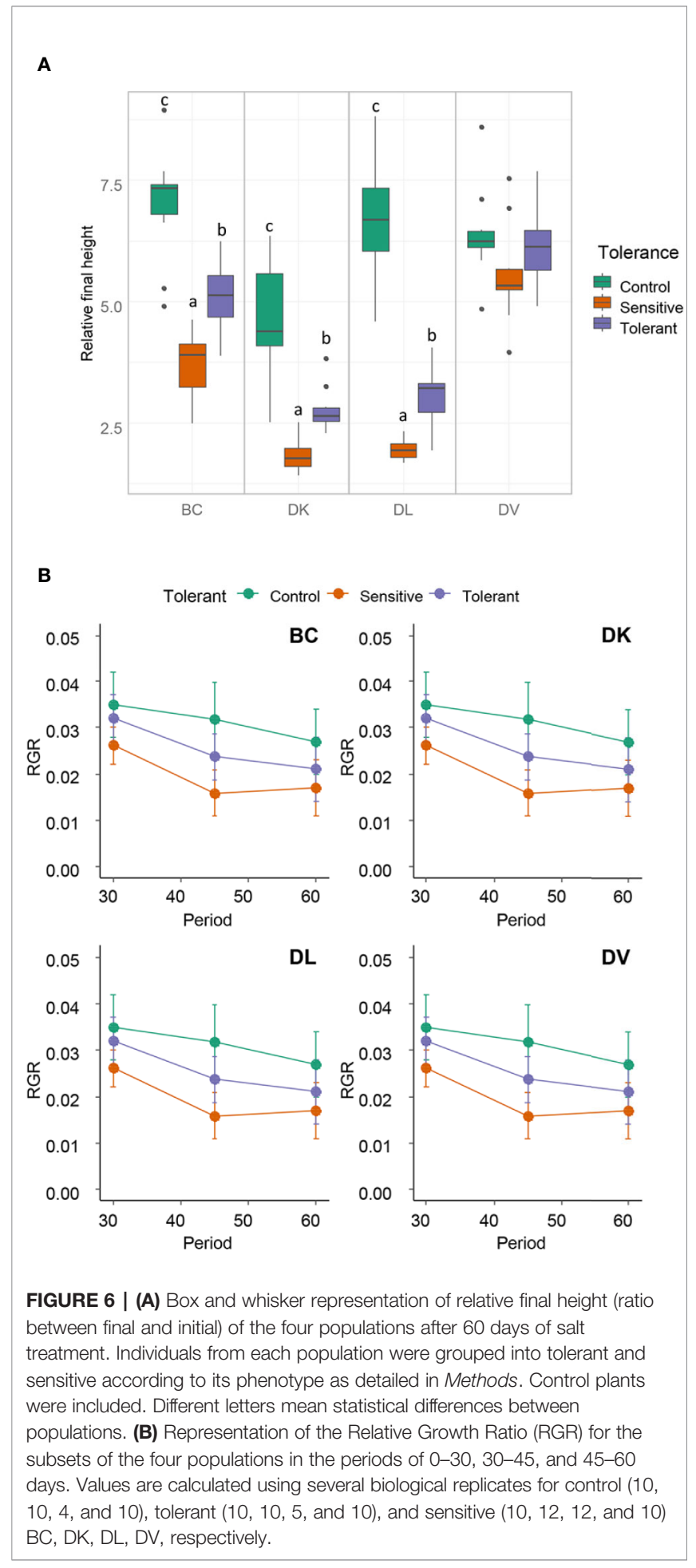

downregulation, whereas PIP2-like 3 showed an upregulation. In roots, a strong (32 fold) downregulation was shown in PIP2-like 6. Both PIP1-like 3 and PIP2-like 3 presented a downregulation in sensitive plants. The DL population showed similar expression differences in roots between tolerant and sensitive to the DK population. In addition, PIP2-like 5 showed less expression in sensitive roots. In leaves of DV population, the only differential

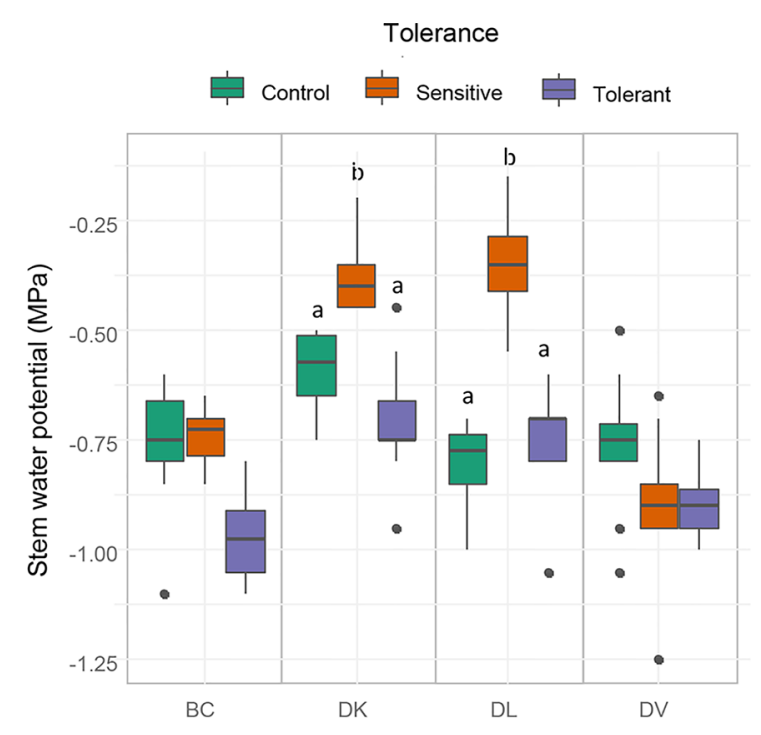

FIGURE 7 | Box and whisker representation of stem water potential of the four populations after 60 days of salt treatment. Genotypes were grouped into tolerant and sensitive according to its phenotype. Control plants were included. Different letters mean statistical differences between populations. Values are calculated using several biological replicates for control (10, 10, 4, and 10), tolerant (10, 10, 5, and 10), and sensitive (10, 12, 12, and 10) BC, DK, DL, DV, respectively.

PIP-like expression between tolerant and sensitive plants was in PIP2-like 1, where the sensitive plants showed a strong upregulation. On roots, PIP1-like 1, PIP2-like 3 and PIP2-like 5 exhibited lower expression in tolerant plants. Regarding to the salt induction of this genes, PIP1-like 1 has shown opposite expression patterns in the $\mathrm{BC}$ and $\mathrm{DK}$ population than the $\mathrm{DL}$ and DV populations.

\section{DISCUSSION}

\section{Saline Stress Effect Among Populations}

The severity of the symptoms in the different populations is coherent with the described differences between these species regarding to salinity tolerance, being $D$. virginiana the most tolerant specie among populations followed by $D$. kaki and $D$. lotus (de Paz et al., 2016b; Visconti et al., 2017; Gil-Muñoz et al., 2018a). The salinity stress results show that the D. kaki most compatible rootstock species (D. kaki, D. lotus and D. virginiana) have much lower salt stress tolerance than other Diospyros species such as black sapote (D. digyna), that even does not show leaf burn when exposed to $16 \mathrm{dS} \mathrm{m} \mathrm{m}^{-1}$ for more than 17 weeks (Mickelbart and Marler, 1998). All the populations exhibited a reduction in the internode length compared to the control. This effect is believed to be caused by the salinity stress response mechanism mediated by DELLA proteins (Achard et al., 2006) as adaption to both saline and osmotic stress via ROS detoxification (Achard et al., 2008). The side effect of DELLA expression would be a reduction in bioactive GAs 

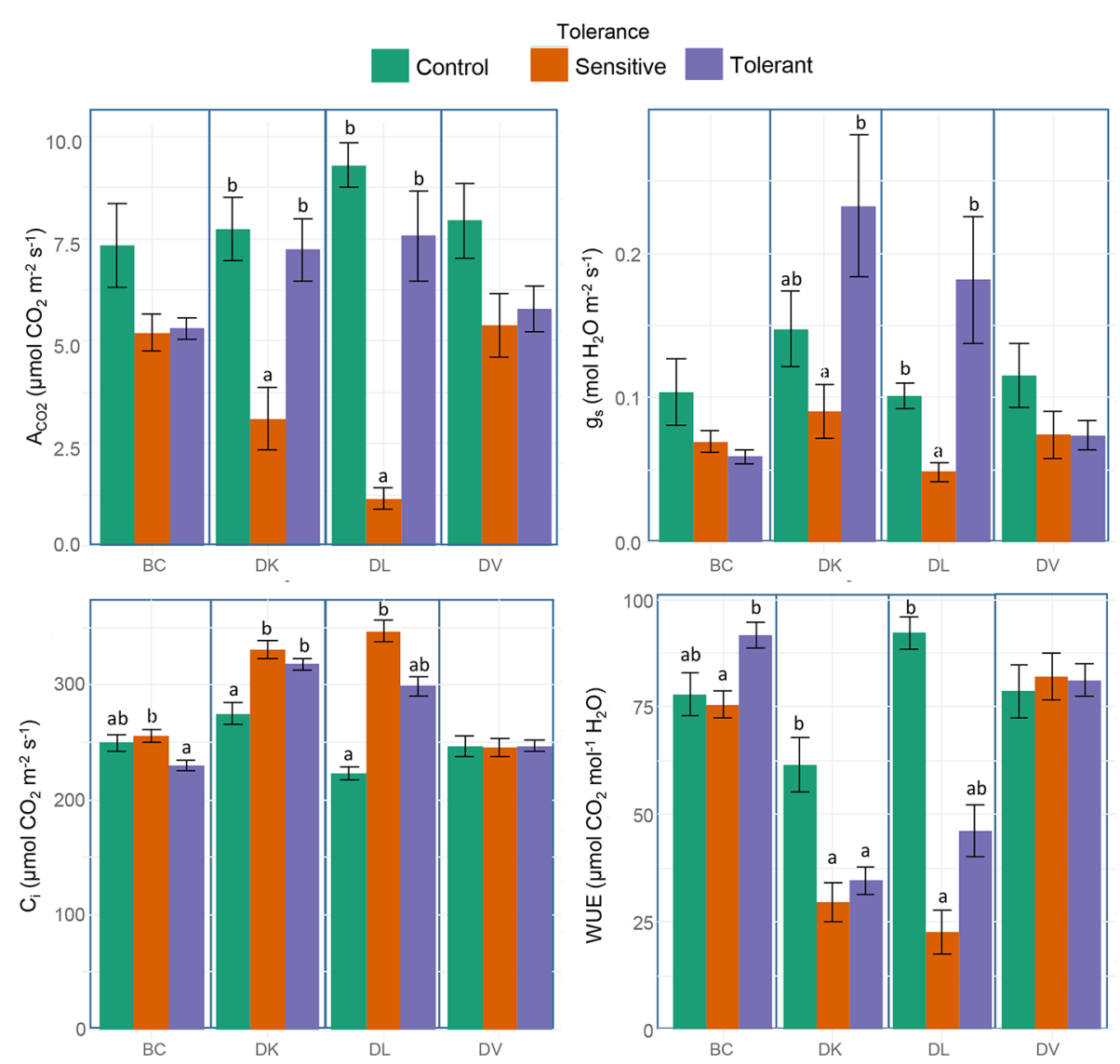

FIGURE 8 | Box and whisker representation of leaf net $\mathrm{CO}_{2}$ assimilation rate $\left(\mathrm{A}_{\mathrm{CO}}\right)$, stomatal conductance $\left(\mathrm{g}_{\mathrm{s}}\right)$, internal $\mathrm{CO}_{2}$ concentration $\left(\mathrm{C}_{\mathrm{i}}\right)$, and intrinsic water use efficiency (WUE) of the four populations after 60 days of salt treatment. Genotypes were grouped into tolerant and sensitive according to its phenotype. Control plants were included. Different letters mean statistical differences between populations. Values are calculated using several biological replicates for control (10, 10, 4, and 10), tolerant $(10,9,5$, and 10), and sensitive $(10,12,11$, and 10) BC, DK, DL, DV, respectively.

(Achard et al., 2006; Magome et al., 2008) causing a reduction in the internode length.

\section{Saline Stress Tolerance Variability Within Populations}

Differences related to the variability of morphological parameters among the three populations studied were obtained. Furthermore, the Principal Component Analysis (PCA), showed the widest distribution in the DV population, whereas the narrowest corresponded to the DL population. Differences in variability can be explained by the genetic structure of each population; DV population comes from an open pollination family, whereas DL is formed by full siblings. Interestingly, DK population is an open pollination family, but shows narrower variability than DV population. This fact can be explained by the low genetic variability previously described for D. kaki (Naval et al., 2010; Parfitt et al., 2015; Gil-Muñoz et al., 2018b). BC population shows an intermediate variability between DV and DK as expected because it combines both genetic backgrounds.
The variability observed in the analyzed parameters is consistent with the population genetic structures. This fact can indicate that a significant percentage of the observed variability might be controlled by genetic traits. The PCA analysis has been also consistent with the genetic structure of the populations, and it can be a useful tool to aid selection during a plant breeding program, as it extracts, compresses, simplifies, and analyzes complex multidimensional datasets (Das et al., 2017). Furthermore, with large datasets, some collinearity is expected to be present among the measured variables. Thus, measurement errors and phenotyping noise can be reduced by PCA projection, providing more precise individual phenotyping. Furthermore, the PCA can provide the importance of easy-measurable variables to the overall desired trait, giving a powerful aid in the selection.

\section{Physiological and Nutritional Effects Related to Salinity Tolerance}

Differences in vegetative development between tolerant and sensitive subsets in both DL and DK populations can be explained by the effect of a poor adaption to the osmotic 


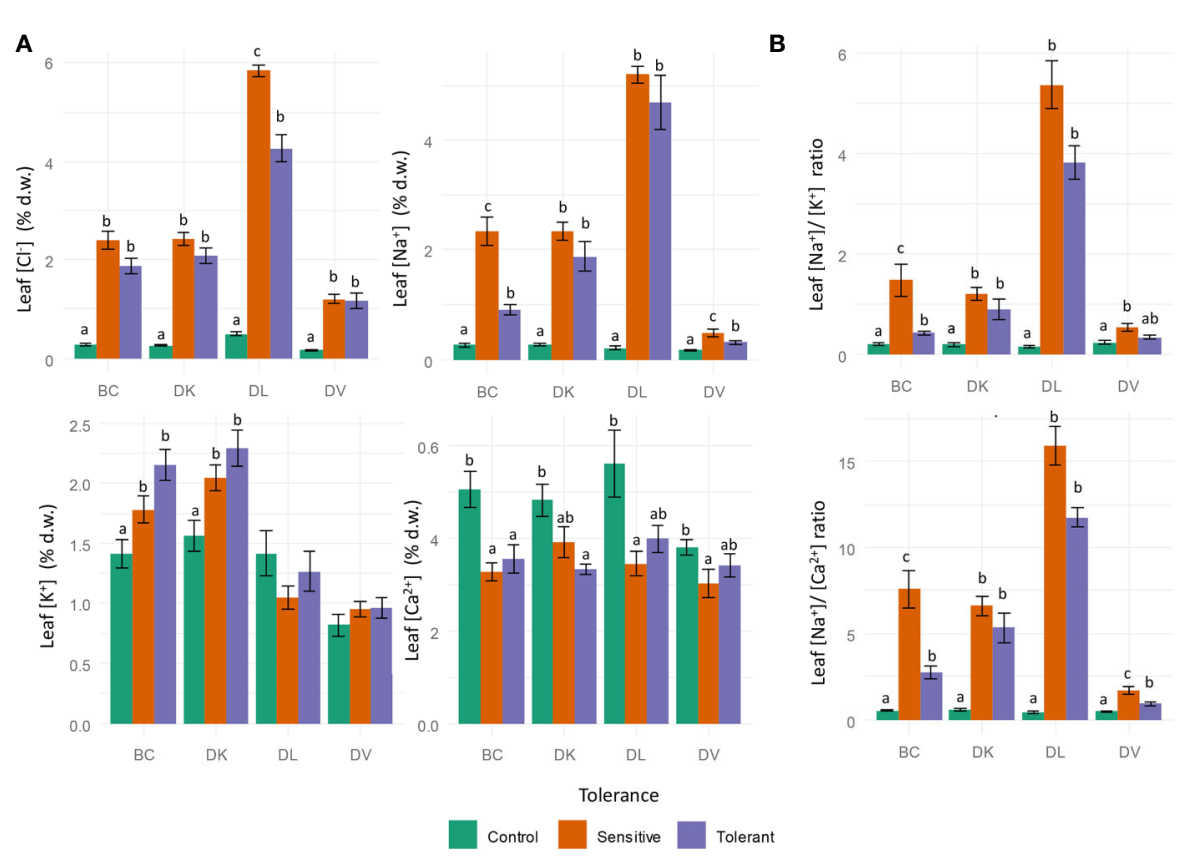

FIGURE 9 | Leaf ion content measurements after 60 days of salinity treatment. $\mathrm{Cl}^{-}, \mathrm{Na}^{+}, \mathrm{K}^{+}$, and $\mathrm{Ca}^{2+}$ (A) and $\mathrm{Na}^{+} / \mathrm{K}^{+}$and $\mathrm{Na}^{+} / \mathrm{Ca}^{2+}$ ratios (B). Genotypes were grouped into tolerant and sensitive according to its phenotype. Control plants were included. Different letters mean statistical differences between populations. Values are calculated using several biological replicates for control (10, 10, 4, and 10), tolerant $(9,9,5$, and 10), and sensitive (10, 10, 12, and 9) BC, DK, DL, DV, respectively.

TABLE 2 | Relative ionic content of each tolerant and sensitive populations compared to control.

\begin{tabular}{|c|c|c|c|c|c|c|c|c|}
\hline & \multicolumn{2}{|c|}{ BC } & \multicolumn{2}{|c|}{ D. kaki } & \multicolumn{2}{|c|}{ D. lotus } & \multicolumn{2}{|c|}{ D. virginiana } \\
\hline $\mathrm{Cl}^{-}$ & + & + & + & + & + & ++ & + & + \\
\hline $\mathrm{Na}^{+}$ & + & ++ & + & + & + & + & + & ++ \\
\hline $\mathrm{K}^{+}$ & ++ & + & + & + & $=$ & $=$ & $=$ & $=$ \\
\hline $\mathrm{Ca}^{2+}$ & - & - & - & $=$ & $=$ & - & $=$ & - \\
\hline
\end{tabular}

Two signs refer to statistically different concentrations between tolerant and sensitive.

stress, as shown by changes in plant water status and the lower photosynthesis rate. However, which one is the cause and which one the effect is not yet known (Munns and Tester, 2008). Nevertheless, ABA contributes to stress tolerance by regulating water balance and stomatal closure (Lim et al., 2015). However, our results show higher stomatal closure in sensitive than in tolerant plants, indicating that the sensitive populations have suffered higher saline stress. On the other hand, differences in photosynthesis, stomatal aperture, or water relations between tolerant and control plants are not observed, indicating that the tolerant subsets had a better response to the osmotic stress than the sensitive subsets in both populations. Furthermore, differences were neither observed between tolerant and control final internode relative length, discarding DELLA response as a mechanism effect. All facts indicate that the observed differences in growth rate and relative final height between tolerant and control plants must be mainly related to ionic stress, which affects growth in a different way than osmotic stress (Munns and Tester, 2008). Respect to the BC population, no differences in parameters as relative growth and growth rate, photosynthesis, stomatal aperture, or water relations were obtained in the analyzed subsets. This may indicate that both tolerant and sensitive plants are not strongly affected by the osmotic stress but rather the ionic stress and differences between these groups might be related to ion exclusion. The DV population has proven to be highly tolerant to saline stress as previously described (de Paz et al., 2016b; Gil-Muñoz et al., 2018a). The similar growth rates and relative final weight among the subsets while maintaining photosynthesis, stomatal aperture, and plant water status indicate the presence of highly efficient mechanisms to overcome osmotic and saline stress. 


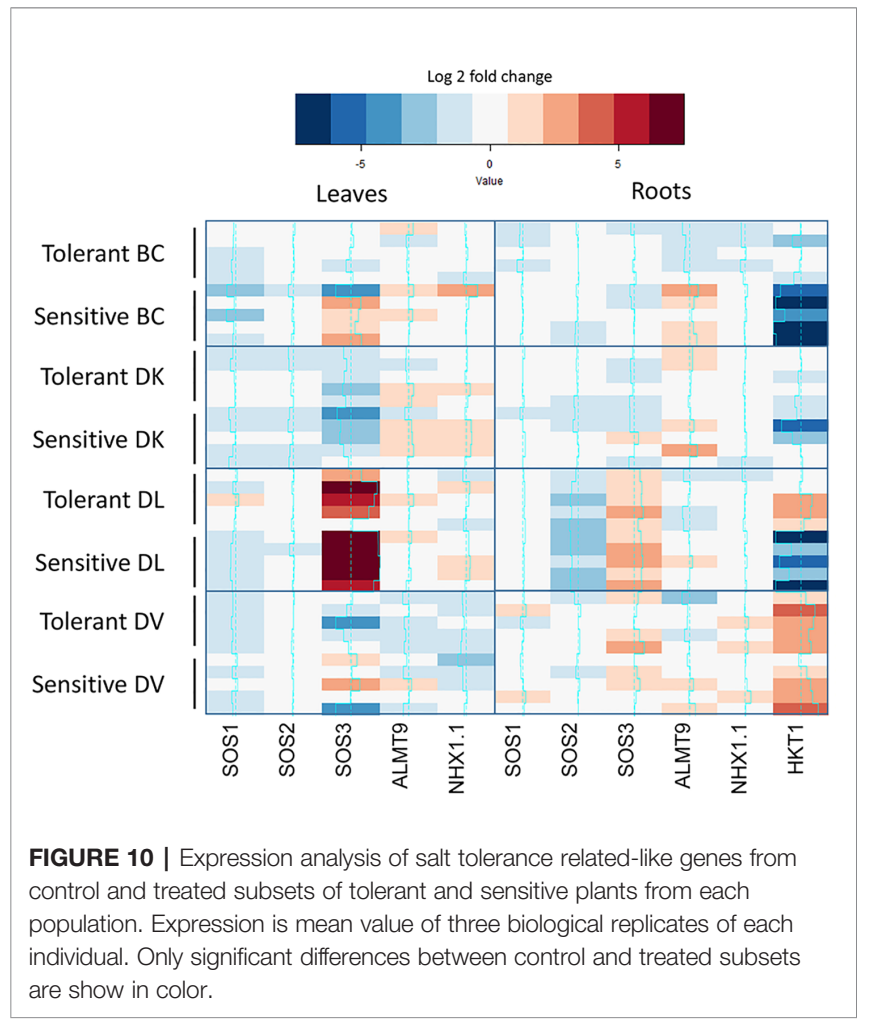

As foliar contents of $\mathrm{Na}^{+}$and $\mathrm{Cl}^{-}$have been analyzed, other mechanisms such as vacuolar sequestration have not been detected that could further explain the differences observed. Our aim has been to study intake and root to shoot exclusion mechanisms taking into account the background objective of breeding rootstock plant, as different scions might have different responses mechanisms of vacuolar ion sequestration. Variability in osmotic stress tolerance is present within $\mathrm{DK}, \mathrm{DL}$, and $\mathrm{BC}$ populations and in $\mathrm{Cl}^{-}$uptake within $\mathrm{DL}$ population. The differences for $\mathrm{Na}^{+}$exclusion observed within $\mathrm{BC}$ population but not in DV and DK populations indicate that DV and DK populations have different $\mathrm{Na}^{+}$exclusion mechanisms, being the DV mechanism more efficient. Further crosses between DL and DV might reveal variability in $\mathrm{Cl}^{-}$exclusion mechanisms that might help to untangle the salt tolerance mechanisms present in Diospyros genus.

\section{Differential Expression of Genes Related to Salinity Tolerance}

Regarding to salt tolerance-related genes expression, a strong upregulation of SOS3-like gene has been observed in the DL population on both tolerant and sensitive plants. This gene is responsible for activating the SOS salinity response mechanism when a low $\mathrm{Ca}^{2+}$ concentration is detected in the cell (Gong et al., 2004). Interestingly, DL population showed similar $\mathrm{Na}^{+}$ accumulation on leaves from control plants than leaves from the end of the salinity experiment. This population presented the highest $\mathrm{Na}^{+}$concentration in leaves and both the highest $\mathrm{Na}^{+} / \mathrm{K}^{+}$ and $\mathrm{Na}^{+} / \mathrm{Ca}^{2+}$. Furthermore, the higher SOS3-like expression present in the sensitive plants leaves of the $\mathrm{BC}$ population, but not in the DK in despite of similar $\mathrm{Na}^{+}, \mathrm{Ca}^{2+}$ and $\mathrm{Na}^{+} / \mathrm{Ca}^{2+}$ levels are observed in the $\mathrm{DK}$ population and $\mathrm{BC}$ sensitive plants. Surprisingly, differences in SOS3-like response are present even though $75 \%$ of the $\mathrm{BC}$ population genome comes from DK population. SOS3-like expression level is upregulated on plants where it can be a response caused by the toxic $\mathrm{Na}^{+}$concentrations in leaves and not a direct indicator of salinity tolerance, s. BC population might have inherited the more sensitive SOS response mechanism present on DV population, whose response has not been observed due to the low levels of $\mathrm{Na}^{+}$in leaves. On the other hand, HKT1-like gene expression differences on roots observed

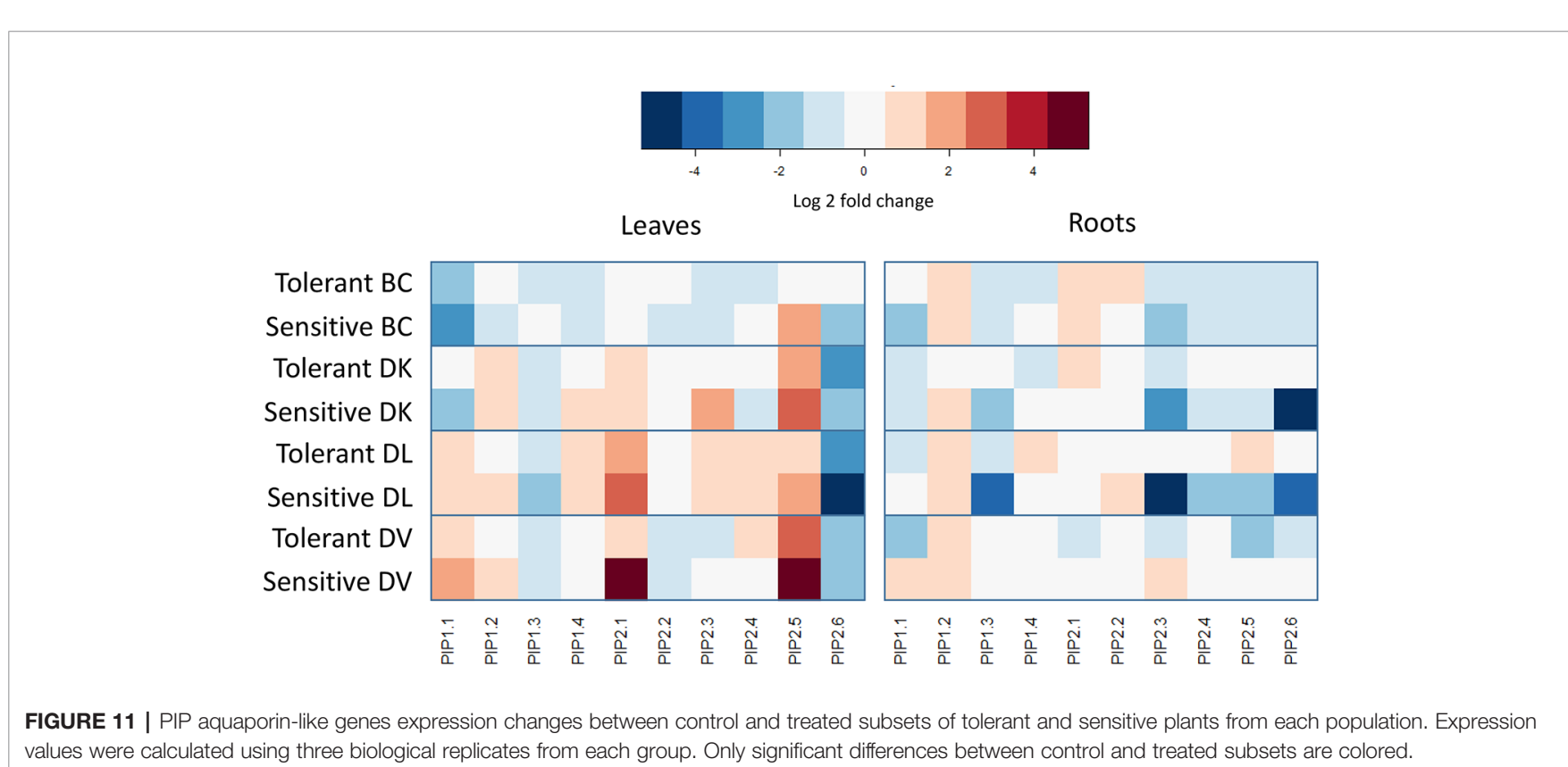


between tolerant and sensitive subsets in BC population were consequent with the tolerant/sensitive phenotype similarly to the observations made in other species (Arabbeigi et al., 2018). HKT1 higher expression could contribute to the salinity tolerance, as this gene is responsible to avoid $\mathrm{Na}^{+}$translocation from roots to shoot via xylem transport (Hanin et al., 2016). PIP gene expression has been linked to an increase in osmotic stress tolerance (Katsuhara et al., 2014; Afzal et al., 2016; Alavilli et al., 2016). In our study, a downregulation in several PIPs has been observed in roots of sensitive subsets of both DL and DK populations where lower stem water potential values were measured. Furthermore, a strong upregulation was observed in some PIP2-like family members on leaves of the sensitive DV subset. In Arabidopsis, the AtPIP2.1 gene has been described to act as a $\mathrm{Na}^{+}$gate to the leaves (Chaumont and Tyerman, 2014).

To sum up, in DK population, we have not observed variability in active $\mathrm{Na}^{+}$or $\mathrm{Cl}^{-}$exclusion mechanisms, but they are present for osmotic stress tolerance via water balance regulation. Regarding to the DL population, we have observed the lowest basal expressions of SOS1-like gene and HKT1-like in roots compared to the other populations. Also, this population has poor ability to exclude $\mathrm{Na}^{+}$ions and therefore prevent toxic concentrations. However, variability in both osmotic stress tolerance via water balance regulation is present. $\mathrm{Cl}^{-}$exclusion variability in this population has been observed, but the mechanism is yet unknown. The DV population tolerance to salinity has been also linked to higher SOS1-like basal expression and HKT1-like upregulation in roots. In other species, the role of this gene is linked to avoid $\mathrm{Na}^{+}$translocation from roots to shoot via xylem transport (Hanin et al., 2016) to the prevention of. Furthermore, in a previous study we observed a higher root expression of HKT1-like gene in a salt-tolerant subset of a Diospyros population (Gil-Muñoz et al., 2020). In addition, variability in the indicators used in this work to identify mechanisms related to salt stress tolerance are not observed within this population.

\section{Conclusions}

Among the different populations studied, different mechanism of tolerance could be hypothesized, providing different strategies for breeding for salinity tolerance.

\section{BC Tolerant Population}

The mechanism of tolerance to osmotic stress found was based in the water use efficiency (WUE). BC tolerant population has shown to have better tolerance to saline stress than sensitive BC through a higher WUE, which agrees with previous results on Diospyrus genus (Gil-Muñoz et al., 2020). Since the lack of variability for this character in the DV and DK populations, we can conclude the variability into $\mathrm{BC}$ has been generated through crossing. We have generated a tolerant population by back crossing in which the water use efficiency is higher than in DV population, which might be a sign of transgressive segregation through expressing the DV higher tolerance under the DK genetic background. Concerning to ionic stress, the $\mathrm{Na}^{+}$ accumulation was higher in the $\mathrm{BC}$ than in the DV population, indicating other factors involved in $\mathrm{Na}^{+}$absorption. The expression of the genes analyzed resulted in a high expression of HKT1-like in roots of DV population; this gene is being involved in $\mathrm{Na}^{+}$exclusion, which might be a mechanism of preventing $\mathrm{Na}^{+}$translocation to the higher parts of the plant in D. virginiana species.

\section{DK Population}

Little variability was found within the DK population regarding to salinity tolerance, neither by ion leaf content nor salt tolerance gene expression. In this case, the observed differences between tolerant and sensitive subsets might be explained by differences in osmotic stress tolerance, but not in ionic stress. In this population, the tolerance might be based only in plant water regulation via stomatal aperture and water flow.

\section{Population}

Similarly, to the DK population, the tolerance observed in DL population for $\mathrm{Na}^{+}$might be based in passive mechanisms through water regulation. In despite of DL population was the most susceptible to salinity, is the only population that has shown differences in $\mathrm{Cl}^{-}$accumulation. However, with the analyzed data we cannot provide a hypothesis that can explain this fact, as water flow differences were similar than the observed in DK population and this differences in $\mathrm{Cl}^{-}$accumulation were not detected. Also, the expression analysis revealed high expression of HKT1-like in roots of the tolerant subset despite of it cannot be linked to lower $\mathrm{Na}^{+}$leaf content.

\section{Population}

In this population, variability for saline tolerance was low, most of the plants showed high saline tolerance. Significant $\mathrm{Na}^{+}$accumulation might be related to the higher PIP2-like family expression in leaves, acting as a gate of $\mathrm{Na}^{+}$influx into the leaves.

As a result of the comparison between physiological parameters, transcriptomic analysis and phenotypes under saline conditions, we can conclude that interspecific crosses of D. virginiana can be an option for breeding persimmon rootstocks tolerant to salinity. Crosses with $D$. kaki can provide better rootstock-scion compatibility with varieties than genotypes from D. virginiana. However, further selection of agronomic traits that improve crop management would be most necessary.

\section{DATA AVAILABILITY STATEMENT}

All datasets generated for this study are included in the article/ Supplementary Material.

\section{AUTHOR CONTRIBUTIONS}

$\mathrm{MB}$ and $\mathrm{MN}$ contributed conception and design of study. FG-M performed the experiments, and data analysis. AQ contributed to the data. JP-P and MB contributed to data analysis and interpretation. $\mathrm{MB}$ provided supplies and facilities. FG-M 
wrote the first draft of the manuscript. MB and JP-P revised the manuscript. All authors contributed to the article and approved the submitted version.

\section{FUNDING}

JP-P gratefully acknowledges the postdoctoral contract "Ramón y Cajal” program (RYC-2015-17726), supplied by the Spanish Ministry of Economy, Industry and Competitiveness (MINECO).

FG-M acknowledges the support granted with the $\mathrm{PhD}$ fellowship co-financed by the European Social Fund and the Generalitat Valenciana ACIF/2016/115). The project was partially funded by the IVIA grant 51914 and FEDER funds.

\section{REFERENCES}

Achard, P., Cheng, H., De Grauwe, L., Decat, J., Schoutteten, H., Moritz, T., et al. (2006). Integration of plant responses to environmentally activated phytohormonal signals. Science 311 (5757), 91-94. doi: 10.1126/science.1118642

Achard, P., Renou, J. P., Berthomé, R., Harberd, N. P., and Genschik, P. (2008). Plant DELLAs restrain growth and promote survival of adversity by reducing the levels of reactive oxygen species. Curr. Biol. 18, 656-660. doi: 10.1016/ j.cub.2008.04.034

Afzal, Z., Howton, T. C., Sun, Y., and Mukhtar, M. S. (2016). The roles of aquaporins in plant stress responses. J. Dev. Biol. 4 (1), 9. doi: 10.3390/ jdb4010009

Akagi, T., Ikegami, A., Tsujimoto, T., Kobayashi, S., Sato, A., Kono, A., et al. (2009). DkMyb4 is a Myb transcription factor involved in proanthocyanidin biosynthesis in persimmon fruit. Plant Physiol. 151, 2028-2045. doi: 10.1104/ pp.109.146985

Akagi, T., Henry, I. M., Tao, R., and Comai, L. (2014). A y-chromosome-encoded small RNA acts as a sex determinant in persimmons. Science 346 (6209), 646650. doi: 10.1126/science. 1257225

Alavilli, H., Awasthi, J. P., Rout, G. R., Sahoo, L., Lee, B. H., and Panda, S. K. (2016). Overexpression of a Barley aquaporin gene, HvPIP2;5 confers salt and osmotic stress tolerance in yeast and plants. Front. Plant Sci. 7, 1566. doi: 10.3389/fpls.2016.01566

Almeida, P., Katschnig, D., and de Boer, A. H. (2013). HKT transporters-state of the art. Int. J. Mol. Sci. 14, 20359-20385. doi: 10.3390/ijms141020359

Apse, M. P., Aharon, G. S., Snedden, W. A., and Blumwald, E. (1999). Salt tolerance conferred by overexpression of a vacuolar $\mathrm{Na}+\mathrm{H}+$ antiport in Arabidopsis. Science 285 (5431), 1256-1258. doi: 10.1126/science.285.5431.1256

Arabbeigi, M., Arzani, A., Majidi, M. M., Sayed-Tabatabaei, B. E., and Saha, P. (2018). Expression pattern of salt tolerance-related genes in Aegilops cylindrica. Physiol. Mol. Biol. Plants. 24 (1), 1-73. doi: 10.1007/s12298-0170483-2

Arzani, A., and Ashraf, M. (2016). Smart engineering of genetic resources for enhanced salinity tolerance in crop plants. CRC. Crit. Rev. Plant Sci. 35 (3), 146-189. doi: 10.1080/07352689.2016.1245056

Arzani, A. (2008). Improving salinity tolerance in crop plants: a biotechnological view. Vitr. Cell. Dev. Biol. - Plant. 44, 373-383. doi: 10.1007/s11627-008-9157-7

Badenes, M. L., Naval, M. M., Martínez-Calvo, J., and Giordani, E. (2015). "Material Vegetal y Mejora Genetica," in El cultivo del caqui. Eds. M. L. Badenes, D. Intrigliolo, A. Salvador and A. Vicent (Valencia, Spain: Generalitat Valenciana), 58-80.

Baetz, U., Eisenach, C., Tohge, T., Martinoia, E., and De Angeli, A. (2016). Vacuolar chloride fluxes impact ion content and distribution during early salinity stress. Plant Physiol. 172, 1167-1181. doi: 10.1104/pp.16.00183

Barbier-Brygoo, H., De Angeli, A., Filleur, S., Frachisse, J.-M., Gambale, F., Thomine, S., et al. (2011). Anion channels/transporters in plants: from molecular bases to regulatory networks. Annu. Rev. Plant Biol. 62, 25-51. doi: 10.1146/annurev-arplant-042110-103741

\section{ACKNOWLEDGMENTS}

We acknowledge the technical support provided by M.A. FornerGiner and M.A. Primo-Capella in the Chloride quantification, hydric pressure measurements, and assay assessment. We also acknowledge Lidia López-Serrano for the assessment in measuring leaf gas exchange parameters.

\section{SUPPLEMENTARY MATERIAL}

The Supplementary Material for this article can be found online at: https://www.frontiersin.org/articles/10.3389/fpls.2020.01132/ full\#supplementary-material

Barragán, V., Leidi, E. O., Andrés, Z., Rubio, L., de Luca, A., Fernández, J. A., et al (2012). Ion exchangers NHX1 and NHX2 mediate active potassium uptake into vacuoles to regulate cell turgor and stomatal function in arabidopsis. Plant Cell 24, 1127-1142. doi: 10.1105/tpc.111.095273

Bellini, E., and Giordani, E. (2002). Cultural practices for persimmon production. CIHEAM Options Mediterr. 51, 39-52.

Boursiac, Y., Chen, S., Luu, D. T., Sorieul, M., Van Den Dries, N., and Maurel, C. (2005). Early effects of salinity on water transport in Arabidopsis roots. Molecular and cellular features of aquaporin expression. Plant Physiol. 139, 790-805. doi: 10.1104/pp.105.065029

Byrt, C. S., Platten, J. D., Spielmeyer, W., James, R. A., Lagudah, E. S., Dennis, E. S., et al. (2007). HKT1;5-like cation transporters linked to Na+ exclusion loci in wheat, Nax2 and Kna1. Plant Physiol. 143, 1918-1928. doi: 10.1104/ pp.106.093476

Chaumont, F., and Tyerman, S. D. (2014). Aquaporins: highly regulated channels controlling plant water relations. Plant Physiol. 164, 1600-1618. doi: 10.1104/ pp.113.233791

Das, S., Debojit, S., Chakraborti, I., Roy, N., and Das, S. S. (2017). Principal component analysis in plant breeding. Biomol. Rep.

Davies, W. J., Kudoyarova, G., and Hartung, W. (2005). Long-distance ABA signaling and its relation to other signaling pathways in the detection of soil drying and the mediation of the plant's response to drought. J. Plant Growth Regul. 24, 285-295. doi: 10.1007/s00344-005-0103-1

de Paz, J. M., Visconti, F., Chiaravalle, M., and Quiñones, A. (2016a). Determination of persimmon leaf chloride contents using near-infrared spectroscopy (NIRS). Anal. Bioanal. Chem. 408, 3537-3545. doi: 10.1007/ s00216-016-9430-2

de Paz, J. M., Visconti, F., Tudela, L., Quiñones Oliver, A., Intrigliolo, D., Jordà, M., et al. (2016b). La fitotoxicidad por cloruro en el cultivo del caqui: descripción del problema. Agrícola Vergel: Fruticultura, Horticultura 391, 91-96.

Essah, P. A., Davenport, R., and Tester, M. (2003). Sodium influx and accumulation in arabidopsis. Plant Physiol. 133, 307-318. doi: 10.1104/ pp.103.022178

Forner-Giner, M. A., and Ancillo, G. (2013). "Breeding salinity tolerance in citrus using rootstocks," in Salt stress in plants: signalling, omics and adaptations. (Berlin, Germany: Springer), 355-376. doi: 10.1007/978-1-4614-6108-1_14

Fricke, W., Akhiyarova, G., Wei, W., Alexandersson, E., Miller, A., Kjellbom, P. O., et al. (2006). The short-term growth response to salt of the developing barley leaf. J. Exp. Bot. 57 (5), 1079-1095. doi: 10.1093/jxb/erj095

Gambino, G., Perrone, I., and Gribaudo, I. (2008). A rapid and effective method for RNA extraction from different tissues of grapevine and other woody plants. Phytochem. Anal. 19, 520-525. doi: 10.1002/pca.1078

Gilliam, J. W. (1971). Rapid measurement of chlorine in plant materials. Soil Sci. Soc. Am. J. 35, 512. doi: 10.2136/sssaj1971.03615995003500030051x

Gil-Muñoz, F., Peche, P. M., Climent, J., Forner, M. A., Naval, M. M., and Badenes, M. L. (2018a). Breeding and screening persimmon rootstocks for saline stress tolerance. Acta Hortic. 1195, 105-110. doi: 10.17660/ActaHortic.2018.1195.18 
Gil-Muñoz, F., Zuriaga, E., Badenes, M. L., and Naval, M. M. (2018b). Analysis of genetic diversity among a set of accessions from the IVIA's persimmon collection. Acta Hortic. 1195, 43-50. doi: 10.17660/ActaHortic.2018.1195.7

Gil-Muñoz, F., Pérez-Pérez, J. G., Quiñones, A., Primo-Capella, A., Cebolla, J., Ángeles Forner-Giner, M., et al. (2020). A cross population between D. Kaki, and D. Virginiana shows high variability for saline tolerance and improved salt stress tolerance. PLoS One 15, e0229023. doi: 10.1371/journal.pone.0229023

Giordani, E., Naval, M., and Benelli, C. (2012). In vitro propagation of Persimmon (Diospyros kaki Thunb.). Methods Mol. Biol. (Clifton, N.J.) 11013, 89-98. doi: 10.1007/978-1-62703-074-8_7

Gong, D., Guo, Y., Schumaker, K. S., and Zhu, J. K. (2004). The SOS3 family of calcium sensors and SOS2 family of protein kinases in arabidopsis. Plant Physiol. 134, 919-926. doi: 10.1104/pp.103.037440

Graves, S., Piepho, H.-P., Selzer With Help From Sundar, L., Maintainer, D.-R., and Selzer, L. (2015). Package "multcompView" Visualizations of Paired Comparisons. $R$ Packag. http://CRAN.R-project.org/package $=$ multcompView

Halfter, U. (2000). The Arabidopsis SOS2 protein kinase physically interacts with and is activated by the calcium-binding protein SOS3. Proc. Natl. Acad. Sci. 97, 3735-3740. doi: 10.1073/pnas.040577697

Hanin, M., Ebel, C., Ngom, M., Laplaze, L., and Masmoudi, K. (2016). New insights on plant salt tolerance mechanisms and their potential use for breeding. Front. Plant Sci. 7, 1787. doi: 10.3389/fpls.2016.01787

Hrabak, E. M., Chan, C. W. M., Gribskov, M., Harper, J. F., Choi, J. H., Halford, N., et al. (2003). The Arabidopsis CDPK-SnRK superfamily of protein kinases. Plant Physiol. 132, 666-680. doi: 10.1104/pp.102.011999

Incesu, M., Cimen, B., Yesiloglu, T., and Yilmaz, B. (2014). Growth and photosynthetic response of two persimmon rootstocks (Diospyros kaki and D. virginiana) under different salinity levels. Not. Bot. Horti. Agrobot. ClujNapoca 42, 386-391. doi: 10.1583/nbha4229471

Isayenkov, S. V., and Maathuis, F. J. M. (2019). Plant salinity stress: many unanswered questions remain. Front. Plant Sci. 10, 80. doi: 10.3389/ fpls.2019.00080

Joly, R. J. (1989). Effects of sodium chloride on the hydraulic conductivity of soybean root systems. Plant Physiol. 91, 1262-1265. doi: 10.1104/pp.91.4.1262

Kassambara, A., and Mundt, F. (2017). Package "factoextra" for R: Extract and Visualize the Results of Multivariate Data Analyses. $R$ Packag. version.

Katsuhara, M., Tsuji, N., Shibasaka, M., and Panda, S. K. (2014). Osmotic stress decreases PIP aquaporin transcripts in barley roots but $\mathrm{H} 2 \mathrm{O} 2$ is not involved in this process. J. Plant Res. 127, 787-792. doi: 10.1007/s10265-014-0662-y

Levin, A. D. (2019). Re-evaluating pressure chamber methods of water status determination in field-grown grapevine (Vitis spp.). Agric. Water Manage. 221, 422-429. doi: 10.1016/j.agwat.2019.03.026

Lim, C. W., Baek, W., Jung, J., Kim, J. H., and Lee, S. C. (2015). Function of ABA in stomatal defense against biotic and drought stresses. Int. J. Mol. Sci. 16, 1525115270. doi: 10.3390/ijms160715251

Liu, J., and Zhu, J. K. (1998). A calcium sensor homolog required for plant salt tolerance. Science 280 (5371), 1943-1945. doi: 10.1126/science.280.5371.1943

Liu, J. (2000). The Arabidopsis thaliana SOS2 gene encodes a protein kinase that is required for salt tolerance. Proc. Natl. Acad. Sci. 97, 3730-3734. doi: 10.1073/ pnas.060034197

López-Pérez, L., Martínez-Ballesta, M., del, C., Maurel, C., and Carvajal, M. (2009). Changes in plasma membrane lipids, aquaporins and proton pump of broccoli roots, as an adaptation mechanism to salinity. Phytochemistry 70, 492-500. doi: 10.1016/j.phytochem.2009.01.014

Magome, H., Yamaguchi, S., Hanada, A., Kamiya, Y., and Oda, K. (2008). The DDF1 transcriptional activator upregulates expression of a gibberellindeactivating gene, GA2ox7, under high-salinity stress in Arabidopsis. Plant J. 56, 613-626. doi: 10.1111/j.1365-313X.2008.03627.x

Mangiafico, S. (2018). rcompanion: Functions to Support Extension Education Program Evaluation. Available at: http://rcompanion.org

Martínez-Ballesta, M. C., Aparicio, F., Pallás, V., Martínez, V., and Carvajal, M. (2003). Influence of saline stress on root hydraulic conductance and PIP expression in Arabidopsis. J. Plant Physiol. 160, 689-697. doi: 10.1078/01761617-00861

Maurel, C., Verdoucq, L., Luu, D. -T., and Santoni, V.. (2008). Plant aquaporins: membrane channels with multiple integrated functions. Annu. Rev. Plant Biol. 59, 595-624. doi: 10.1146/annurev.arplant.59.032607.092734
Mickelbart, M. V., and Marler, T. E. (1998). Growth, gas exchange, and mineral relations of black sapote (Diospyros digyna Jacq.) as influenced by salinity. Sci. Hortic. (Amsterdam) 72 (2), 103-110. doi: 10.1016/S0304-4238(97) 00095-2

Munns, R., and Tester, M. (2008). Mechanisms of Salinity Tolerance. Annu. Rev. Plant Biol. 59, 651-681. doi: 10.1146/annurev.arplant.59.032607.092911

Munns, R., Guo, J., Passioura, J. B., and Cramer, G. R. (2000). Leaf water status controls day-time but not daily rates of leaf expansion in salt-treated barley. Aust. J. Plant Physiol. 27, 949-957. doi: 10.1071/pp99193

Naval, M., del, M., Zuriaga, E., Pecchioli, S., Llácer, G., Giordani, E., et al. (2010). Analysis of genetic diversity among persimmon cultivars using microsatellite markers. Tree Genet. Genomes 6, 677-687. doi: 10.1007/s11295-010-0283-0

Neuwirth, E. (2014). RColorBrewer: ColorBrewer palettes. R Packag. version 1.1-2. https://cran.R-project.org/package=RColorBrewer. Available at: https://cran.rproject.org/web/packages/RColorBrewer/index.html.

Ogle, D. H., Wheeler, P., and Dinno, A. (2018). FSA: Fisheries Stock Analysis. $R$ package version 0.8.22. Available at: https://github.com/droglenc/FSA

Parfitt, D. E., Yonemori, K., Honsho, C., Nozaka, M., Kanzaki, S., Sato, A., et al. (2015). Relationships among Asian persimmon cultivars, astringent and non-astringent types. Real-Time Syst. 51, 1-9. doi: 10.1007/s11295-0150848-z

Perucho, R. (2018). "Evolution of production of the 'Rojo Brillante' cultivar in Spain and its impact on markets," in Acta Horticulturae (Leuven, Belgium: International Society for Horticultural Science (ISHS)), 1-8. doi: 10.17660/ ActaHortic.2018.1195.1

Qiu, Q. S., Guo, Y., Dietrich, M. A., Schumaker, K. S., and Zhu, J. K. (2002). Regulation of SOS1, a plasma membrane $\mathrm{Na}+\mathrm{H}+$ exchanger in Arabidopsis thaliana, by SOS2 and SOS3. Proc. Natl. Acad. Sci. U. S. A. 99, 8436-8441. doi: 10.1073/pnas.122224699

Qiu, Q. S., Barkla, B. J., Vera-Estrella, R., Zhu, J. K., and Schumaker, K. S. (2003). $\mathrm{Na}+\mathrm{H}+$ exchange activity in the plasma membrane of Arabidopsis. Plant Physiol. 132, 1041-1052. doi: 10.1104/pp.102.010421

Quan, R., Lin, H., Mendoza, I., Zhang, Y., Cao, W., Yang, Y., et al. (2007). SCABP8/CBL10, a putative calcium sensor, interacts with the protein kinase SOS2 to protect Arabidopsis shoots from salt stress. Plant Cell 19, 1415-1431. doi: 10.1105/tpc.106.042291

Quintero, F. J., Ohta, M., Shi, H., Zhu, J. K., and Pardo, J. M. (2002). Reconstitution in yeast of the Arabidopsis SOS signaling pathway for $\mathrm{Na}+$ homeostasis. Proc. Natl. Acad. Sci. U. S. A. 99, 9061-9066. doi: 10.1073/ pnas.132092099

Quintero, F. J., Martinez-Atienza, J., Villalta, I., Jiang, X., Kim, W. Y., Ali, Z., et al. (2011). Activation of the plasma membrane $\mathrm{Na} / \mathrm{H}$ antiporter salt-overlysensitive 1 (SOS1) by phosphorylation of an auto-inhibitory C-terminal domain. Proc. Natl. Acad. Sci. U. S. A. 108, 2611-2616. doi: 10.1073/ pnas. 1018921108

Rodríguez-Gamir, J., Ancillo, G., Legaz, F., Primo-Millo, E., and Forner-Giner, M. A. (2012). Influence of salinity on pip gene expression in citrus roots and its relationship with root hydraulic conductance, transpiration and chloride exclusion from leaves. Environ. Exp. Bot. 78, 163-166. doi: 10.1016/ j.envexpbot.2011.12.027

Shi, H., Ishitani, M., Kim, C., and Zhu, J. K. (2000). The Arabidopsis thaliana salt tolerance gene SOS1 encodes a putative $\mathrm{Na}+\mathrm{H}+$ antiporter. Proc. Natl. Acad. Sci. U. S. A. 97, 6896-6901. doi: 10.1073/pnas.120170197

Signorell, A. (2017). DescTools: Tools for descriptive statistics. $R$ package version 0.99.20. CRAN. doi: 10.1016/j.foreco.2014.09.033

Termaat, A., Passioura, J. B., and Munns, R. (1985). Shoot Turgor Does Not Limit Shoot Growth of NaCl-Affected Wheat and Barley. Plant Physiol. 77, 869-872. doi: 10.1104/pp.77.4.869

Tiwari, S., Sl, K., Kumar, V., Singh, B., Rao, A. R., Sv, A. M., et al. (2016). Mapping QTLs for salt tolerance in rice (Oryza sativa L.) by bulked segregant analysis of recombinant inbred lines using 50K SNP chip. PLoS One 11, e0153610. doi: 10.1371/journal.pone.0153610

Visconti, F., de Paz, J. M., Bonet, L., Jordà, M., Quiñones, A., and Intrigliolo, D. S. (2015). Effects of a commercial calcium protein hydrolysate on the salt tolerance of Diospyros kaki L. cv. "Rojo Brillante" grafted on Diospyros lotus L. Sci. Hortic. (Amsterdam) 185, 129-138. doi: 10.1016/j.scienta. 2015.01.028 
Visconti, F., Intrigliolo, D. S., Quiñones, A., Tudela, L., Bonet, L., and de Paz, J. M. (2017). Differences in specific chloride toxicity to Diospyros kaki cv. "Rojo Brillante" grafted on D. lotus, and D. virginiana. Sci. Hortic. (Amsterdam) 214, 83-90. doi: 10.1016/j.scienta.2016.11.025

Wang, P., Xiong, A., Gao, Z., Yu, X., Li, M., Hou, Y., et al. (2016). Selection of suitable reference genes for RTqPCR normalization under abiotic stresses and hormone stimulation in persimmon (Diospyros kaki Thunb). PLoS One 11 (8), e160885. doi: 10.1371/journal.pone.0160885

Warnes, G. R., Bolker, B., Bonebakker, L., Gentleman, R., Liaw, W. H. A., Lumley, T., et al. (2016). Package "gplots": various R programming tools for plotting data. $R$ Packag. version 2.17.0. doi: 10.1111/j.0022-3646.1997. 00569.x

Wei, T., and Simko, V. (2016). Visualization of a Correlation Matrix: Package "corrplot." CRAN Comprehensive R Archive Network 1-17. Available at: https:// cran.r-project.org/package $=$ corrplot

Wickham, H., François, R., Henry, L., and Müller, K. (2018). Package "dplyr."

Wickham, H. (2016). ggplot2 Elegant Graphics for Data Analysis. (Berlin, Germany: Springer). doi: 10.1007/978-3-319-24277-4
Zekri, M., and Parsons, L. R. (1989). Growth and root hydraulic conductivity of several citrus rootstocks under salt and polyethylene glycol stresses. Physiol. Plant 77, 99-106. doi: 10.1111/j.1399-3054.1989.tb05984.x

Zhu, J. K., Liu, J., Xiong, L., and Santoni, V. (1998). Genetic analysis of salt tolerance in arabidopsis: evidence for a critical role of potassium nutrition. Plant Cell 10, 1181-1191. doi: 10.1105/tpc.10.7.1181

Conflict of Interest: The authors declare that the research was conducted in the absence of any commercial or financial relationships that could be construed as a potential conflict of interest.

Copyright (C) 2020 Gil-Muñoz, Pérez-Pérez, Quiñones, Naval and Badenes. This is an open-access article distributed under the terms of the Creative Commons Attribution License (CC BY). The use, distribution or reproduction in other forums is permitted, provided the original author(s) and the copyright owner(s) are credited and that the original publication in this journal is cited, in accordance with accepted academic practice. No use, distribution or reproduction is permitted which does not comply with these terms. 